\title{
Clavulanic Acid Production by Streptomyces clavuligerus: Insights from Systems Biology, Strain Engineering, and Downstream Processing
}

\author{
Víctor A. López-Agudelo ${ }^{1}$ (D), David Gómez-Ríos ${ }^{2}$ (D) and Howard Ramirez-Malule ${ }^{1, *(D)}$ \\ 1 Escuela de Ingeniería Química, Universidad del Valle, A.A., Cali 25360, Colombia; viclopezag@gmail.com \\ 2 Grupo de Investigación en Simulación, Diseño, Control y Optimización de Procesos (SIDCOP), Departamento \\ de Ingeniería Química, Universidad de Antioquia UdeA, Calle 70 No. 52-21, Medellín 050010, Colombia; \\ dandres.gomez@udea.edu.co \\ * Correspondence: howard.ramirez@correounivalle.edu.co; Tel.: +57-2-3212100 (ext. 7367)
}

Citation: López-Agudelo, V.A.; Gómez-Ríos, D.; Ramirez-Malule, H. Clavulanic Acid Production by Streptomyces clavuligerus: Insights from Systems Biology, Strain Engineering, and Downstream Processing. Antibiotics 2021, 10, 84. https://doi.org/10.3390/antibiotics 10010084

Received: 23 December 2020

Accepted: 12 January 2021

Published: 18 January 2021

Publisher's Note: MDPI stays neutral with regard to jurisdictional claims in published maps and institutional affiliations.

Copyright: (C) 2021 by the authors. Licensee MDPI, Basel, Switzerland. This article is an open access article distributed under the terms and conditions of the Creative Commons Attribution (CC BY) license (https:// creativecommons.org/licenses/by/ $4.0 /)$.

\begin{abstract}
Clavulanic acid (CA) is an irreversible $\beta$-lactamase enzyme inhibitor with a weak antibacterial activity produced by Streptomyces clavuligerus (S. clavuligerus). CA is typically co-formulated with broad-spectrum $\beta$-lactam antibiotics such as amoxicillin, conferring them high potential to treat diseases caused by bacteria that possess $\beta$-lactam resistance. The clinical importance of CA and the complexity of the production process motivate improvements from an interdisciplinary standpoint by integrating metabolic engineering strategies and knowledge on metabolic and regulatory events through systems biology and multi-omics approaches. In the large-scale bioprocessing, optimization of culture conditions, bioreactor design, agitation regime, as well as advances in CA separation and purification are required to improve the cost structure associated to CA production. This review presents the recent insights in CA production by S. clavuligerus, emphasizing on systems biology approaches, strain engineering, and downstream processing.
\end{abstract}

Keywords: clavulanic acid; Streptomyces clavuligerus; systems biology; strain engineering; downstream processing

\section{Introduction}

The accessibility to effective treatment alternatives of infectious diseases depends on the availability of appropriate antibiotic compounds in the market. Efficient antibiotic production is crucial for health systems worldwide, especially in outbreaks, epidemics, and health emergencies, in which the antibiotic supply chain can be put under pressure.

Additionally, the acquired antibiotic resistance phenomenon became a global concern as it may increase the vulnerability of health systems [1]. The antibiotic resistance phenomenon emerged along with the antibiotic era [2,3]. Years before penicillin was used at global scale, a penicillinase enzyme able to inactivate penicillin was discovered in bacteria extracts [4]. Antibiotic resistance has forced humanity to maintain an endless search for new and more powerful antibiotics. In this regard, the pharmaceutical industry plays a key role in the development of effective treatments against such multidrug-resistant bacteria [1]. Since the discovery of benzylpenicillin in the 1920s, the class of compounds referred to as $\beta$-lactam antibiotics has been the most extensively used antibiotics. Nevertheless, a significant number of different antibiotic compounds (such as carbapenems, cephamycins, cephalosporins, and monobactams) has been developed and implemented in the clinical practice as a strategy to evade the acquired resistance [5]. The new combinations of antibiotics are aimed to increase their spectrum of activity and overcome the resistance barriers developed by the bacteria. In order to mitigate the bacterial resistance to $\beta$-lactam antibiotics, several compounds have been identified as $\beta$-lactamase inhibitors. Those compounds can irreversibly inactivate the $\beta$-lactamases allowing the $\beta$-lactam antibiotics to 
act against the infection. The main $\beta$-lactamase inhibitors are Sulbactam, Tazobactam, and clavulanic acid (CA) as clavulanate salt.

CA is a $\beta$-lactam compound with modest antibiotic activity but high inhibition capacity of $\beta$-lactamase enzymes. The CA molecule is an analog of the penicillin nucleus, in which the characteristic sulfur atom has been substituted by an oxygen atom. CA is one of the so-called "clavam metabolites" produced by the filamentous bacterium Streptomyces clavuligerus (S. clavuligerus); most of those metabolites have the characteristic fused bicyclic $\beta$-lactam/oxazolidine ring. Nevertheless, the CA molecule (Figure 1) has 3R, $5 \mathrm{R}$ stereochemistry, opposite to the $3 \mathrm{~S}, 5 \mathrm{~S}$ configuration present in other clavam metabolites, which do not exhibit $\beta$-lactamase inhibition activity, although some of them have antibacterial or antifungal properties [6]. In addition to the stereochemistry, the inhibitory effect of CA has been explained by the presence of the $\beta$-lactam/oxazolidine ring that bonds irreversibly with a serine residue in the catalytic center of the $\beta$-lactamase enzyme, thus rendering it inactive [7]. Currently, CA is used in combination with other $\beta$-lactam antibiotics as an effective treatment against several clinical syndromes including pneumonia and exacerbations of chronic obstructive pulmonary disease, complicated intra-abdominal infections, acute infectious diarrhea, urinary tract infections, pharyngitis, surgical, wound, and skin infections [8]. Some of them are caused by resistant pathogenic bacteria already included in the World Health Organization priority list: Escherichia coli, Staphylococcus aureus, Neisseria gonorrhoeae, Streptococcus pneumonia, and all Enterobacteriaceae and Klebsiella species [1].<smiles>O=C(O)[C@H]1/C(=C\CO)O[C@@H]2[CH]CC(=O)N21</smiles>

Clavulanic acid

Figure 1. Clavulanic acid (CA) structure. Red and blue $C$ atoms correspond to those coming from C-3 and C-5 precursors, respectively. ${ }^{*}$ Stereochemical centers on CA structure.

CA is produced worldwide at large scale by several pharmaceutical companies, and it is also prescribed in more than 150 countries [9]. CA has a relatively limited market availability and a middle-high cost for the health system, especially in the developing countries when compared with the income level, being quite inaccessible for people without health insurance. The cost of CA is mainly related to the complexity of the production process, the current uncertainties about the regulatory elements controlling the CA biosynthetic gene cluster and the intellectual property associated with its production [6]. Despite the significant number of studies related to CA production in S. clavuligerus submerged cultivations, low titers $\left(\sim 1 \mathrm{~g} \cdot \mathrm{L}^{-1}\right)$ are still obtained when using a wild type strain. The productivity of CA production bioprocess is also compromised by the downstream processing: CA separation from fermentation broths and precipitation as clavulanate salt. This review presents a holistic overview of CA production process: CA biosynthesis; CA production in S. clavuligerus submerged cultivation; recent advances in strain engineering; and elucidation of regulatory elements controlling CA production, systems biology approaches, and downstream processing (Figure 2). 


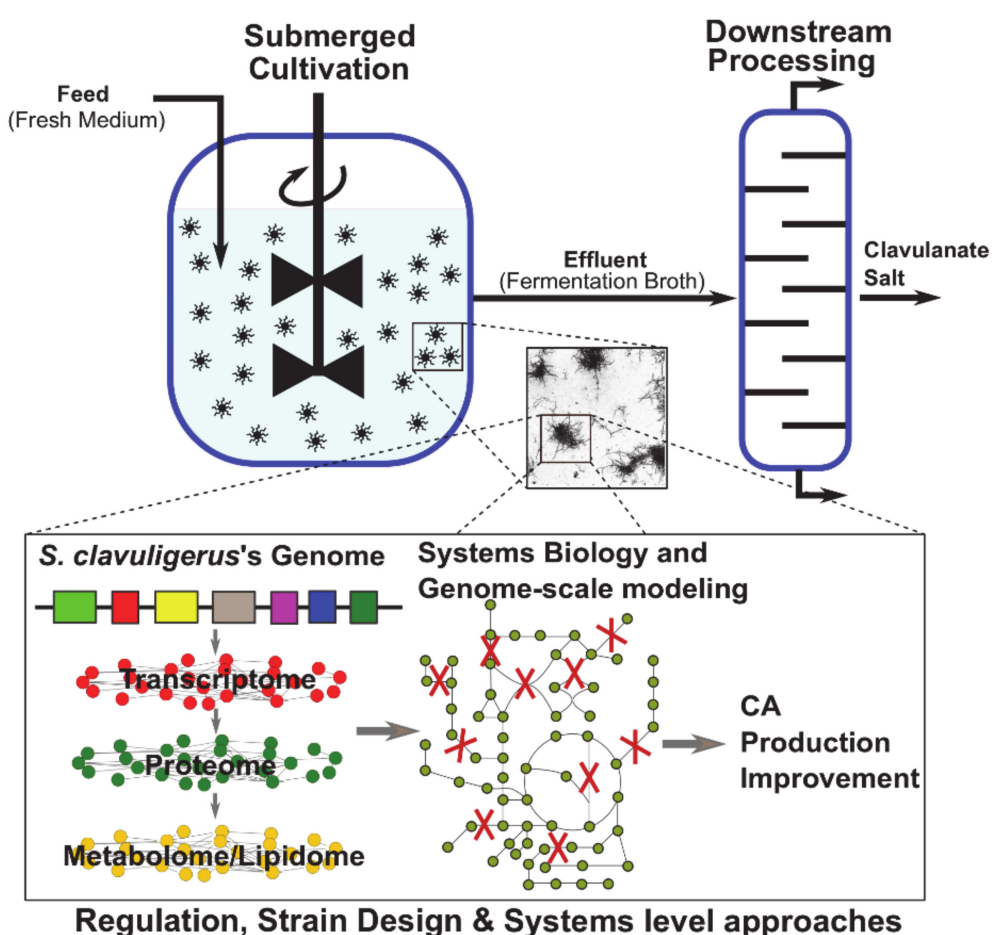

Figure 2. Holistic overview of the CA production process.

\section{Overview of CA Biosynthesis in S. clavuligerus}

The Streptomyces genus produces a wide variety of secondary metabolites with antimicrobial activity (approximately two-thirds of which occur naturally) [10]. In 1971, Nagarajan et al. [11] reported a new Streptomycete species as producer of two cephalosporin compounds. This new species was then named and described as S. clavuligerus by Higgens and Kastner, also in 1971 [12]. Later, in 1976, Howarth and Brown [13] described the CA chemical structure, which was elucidated via spectroscopic and X-ray analyses and reported as a novel fused $\beta$-lactam compound with a significant inhibitory activity of $\beta$-lactamases. In 1977, Reading and Cole described the cultivation conditions of S. clavuligerus to produce CA and the spectrometric method for CA detection [7].

In 1941, the biochemist Selman Waskman described the most accepted definition of "antibiotic" as a small molecule made by microorganisms that inhibits the growth of another microorganism. During the "golden age" of antibiotics, approximately 70-80\% of the antibiotics discovered came from Streptomycetes, but the evolutionary reason for the development of antibiotic biosynthetic capacity of soil bacteria and its ecological role are still unknown. Soil bacteria are not very efficient at up-taking nutrients, and their growth rate is considerably low in comparison with other bacteria and fungi. A plausible hypothesis that iswidely accepted implies that antibiotics secretion allows the producer to control the organisms competing for the same nutritional resources in a hostile multispecies environment $[2,14]$. This is consistent with the secondary nature of antibiotics secretion under nutritional restriction. However, the antibiotic compounds at very low concentrations can modulate the transcriptional profiles of target bacteria and the products of resistance genes would silence those messages, opposing the theory of the development of attack and defense mechanisms [14]. Mathematical estimations point out that Streptomycetes are able to produce around 100,000 antibiotics and only 3\% of them have been discovered [15]. Similarly, the existence of cryptic biosynthetic gene clusters (BGCs) suggests a higher capacity of antibiotic production in those organisms [16-18].

CA is secreted as a secondary metabolite, also referred as a specialized metabolite, by $S$. clavuligerus under nutritional restriction. The role of CA in the physiology and adaptation of $S$. clavuligerus is also unknown. As a $\beta$-lactamase inhibitor, CA may be part of a self-resistance mechanism involving the synthesis of $\beta$-lactam antibiotics, $\beta$-lactamase 
enzymes, and $\beta$-lactamase inhibitors; possibly developed by Streptomyces species to defend themselves from the effect of the antimicrobials [10]. CA biosynthesis is induced during phosphate limited conditions; recently it has been proposed that CA production may be a consequence of a homeostatic response aimed to compensate for the ATP deficit under phosphate depletion [19]. This mechanism would trigger a strong activation of oxidative and amino acid metabolism, producing reduced cofactors and ATP and favoring the antibiotic biosynthesis as a feasible mechanism to adjust the ATP generation $[20,21]$. Moreover, the simultaneous secretion of penicillin and cephalosporins antibiotics along with $\beta$-lactamase enzymes and $\beta$-lactamase inhibitors would tightly control the energetic impact of an ATP-consuming futile cycle of polymerization/degradation of the cell wall caused by the $\beta$-lactam antibiotics accumulation $[19,22,23]$.

CA is a product of the clavam pathway, which proceeds towards two branches: the CA and the clavams $5 S$ biosynthesis [6]. The clavam pathway contains two sets of reactions: the so-called "early" and "late" steps. The early steps start with the condensation of the glycolysis intermediate glyceraldehyde-3-phosphate and the amino acid L-arginine, producing the $N^{2}$-(2-carboxyethyl)-arginine. This condensation is catalyzed by the $N^{2}$-(2-carboxyethyl)arginine synthase (CEAS). The early steps comprise five well-known reactions leading to the $(3 S, 5 S)$-clavaminic acid. The formation of the clavaminic acid is considered a bifurcation point of the carbon flowing through the pathway. The CA biosynthesis late steps consider the reactions leading to $\mathrm{CA}$, as well as the reactions forming the clavam $5 S$ compounds after the clavaminic acid bifurcation [24-26]. The known reactions of the clavam pathway are summarized in Figure 3. The $\beta$-lactam compound deoxyguanidinoproclavaminic acid is synthesized from the $N^{2}$-(2-carboxyethyl)-arginine in the second reaction of the clavam pathway, catalyzed by the $\beta$-lactam synthetase (BLS) [27-29]. The hydroxylation of the deoxyguanidinoproclavaminic acid takes place to form the guanidinoproclavaminic acid; a reaction mediated by clavaminate synthase (CAS) [29-32]. Subsequently, the proclavaminic acid is produced by removing the amidino group from the arginine residue on the guanidinoproclavaminic acid, by action of proclavaminate amidino hydrolase (PAH) [33,34]. The dihydroclavaminic acid is obtained from the proclavaminic acid through oxidative cyclization and desaturation, both catalyzed by CAS, leading to the $(3 S, 5 S)$-clavaminic acid $[29,35]$. At this point, the late steps start with the carbon flux bifurcation in two branches: one branch leading to the clavulanate-9-aldehyde and further the CA, and the other branch forming clavam $5 \mathrm{~S}$ compounds. It is important to highlight that the 3S, $5 S$ stereochemistry of clavaminic acid is conserved in the synthesis of all clavam $5 S$ compounds. In the case of the $C A$, a transition from $3 S, 5 S$ configuration to $3 R, 5 R$ is required. Some authors have suggested that this stereochemical inversion may occur via the N-glycyl-clavaminic acid intermediate to form the clavulanate-9-aldehyde with a 3R, $5 R$ configuration, and therefore the CA [36,37]. However, more experimental evidence is required for the complete elucidation of intermediate reactions connecting the clavaminic acid with the clavulanate-9-aldehyde [36,37], which is lastly reduced to CA by the action of clavulanate dehydrogenase (CAD) [38]. Recently, Gómez et al. [39] proposed six reaction steps for the $3 S, 5 S$ to the $3 R, 5 R$ transition, by using a computational approach.

In addition to the CA, other metabolites have been identified as side compounds of this biosynthetic pathway, namely, N-glycyl-clavaminic acid, N-acetylglycyl-clavaminic acid, and N-acetyl-clavaminic acid. It has been suggested that those compounds result from the intermediate steps involved in the transition of the 3S, 5S stereochemistry into the 3R, 5R of CA [36]. Additionally, several metabolites (2-hydroxymethylclavam, 2-formyloxymethylclavam, clavam-2-carboxylic acid, and alanylclavam) have been identified and grouped as clavam $5 S$ compounds due to their 3S, 5 S stereochemistry $[37,40,41]$. Despite their structural similarity and common precursors, only the clavam compounds with a bicyclic nucleus formed by the $\beta$-lactam ring and an oxazolidine ring with $3 R, 5 R$ stereochemistry can effectively inhibit the $\beta$-lactamases $[10,40]$.

Glycerol is the main substrate in the CA production by S. clavuligerus as it has direct incorporation into the glycolytic pathway by forming glyceraldehyde 3-phosphate, the first 
C-3 precursor of CA [42,43]. Then, the carbon flux splits into three pathways, two of them belonging to the primary metabolism: glycolysis and gluconeogenesis, and one belonging to the secondary metabolism: the clavam pathway [43-45]. In addition to glyceraldehyde 3-phosphate, the need for a C-5 precursor implies the constant demand for L-arginine. This amino acid is synthesized in the urea cycle while L-glutamate and L-aspartate promote its biosynthesis by fueling the urea cycle in the oxidative direction [42-44].

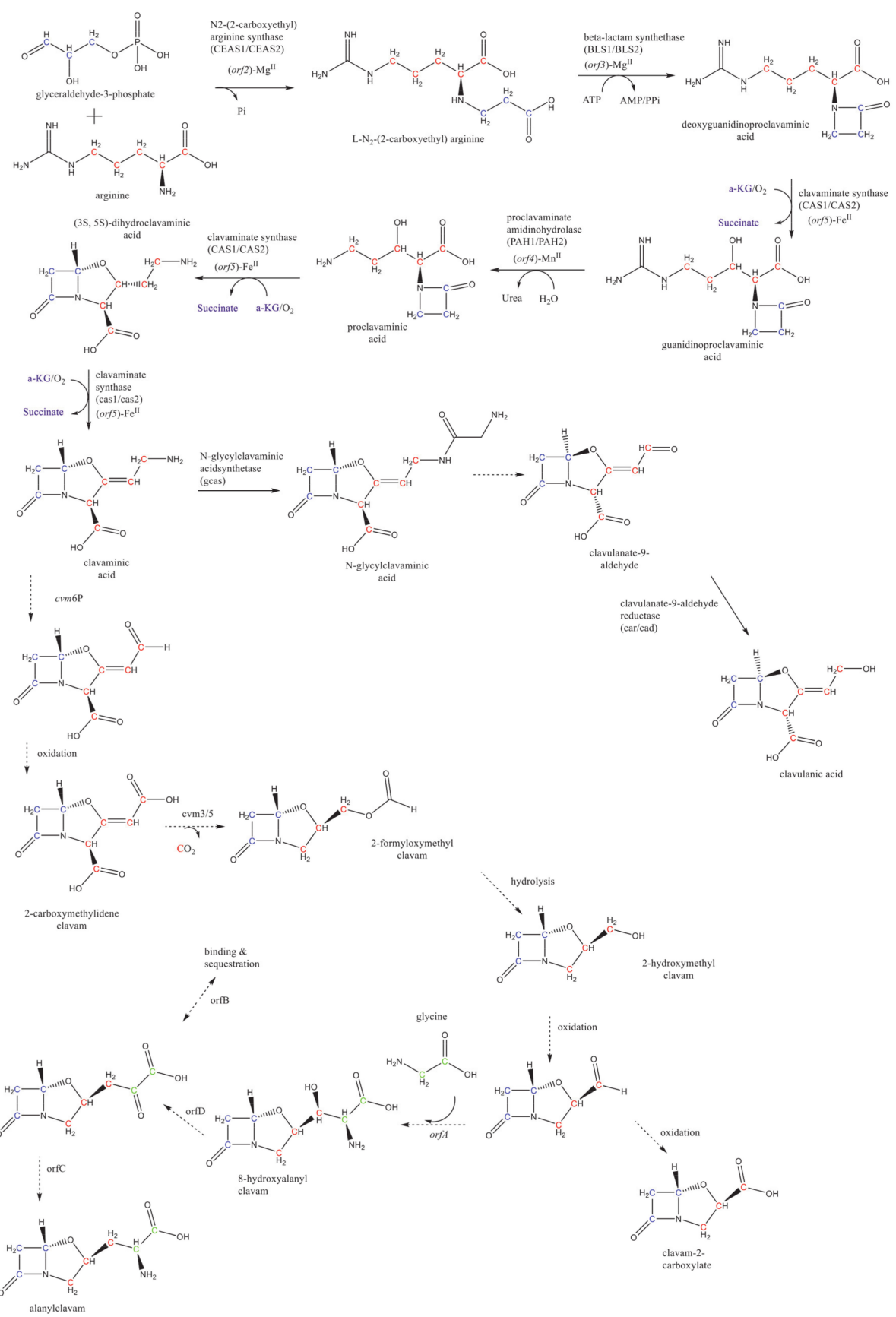

Figure 3. Summary of the CA biosynthetic pathway in S. clavuligerus. The green, blue, and red Cs represent the carbon atoms coming from metabolic intermediates such as glycine, glyceraldehyde 3-phosphate, and L-arginine, respectively. Adapted from the work in [43]. 


\section{CA Production in S. clavuligerus Submerged Cultivation}

Besides CA, S. clavuligerus produces a plethora of secondary metabolites that can compete with CA biosynthesis and secretion. Those include some $\beta$-lactam (penicillin $\mathrm{N}$, cephamicin $C$, cephalosporins, and other clavams) and non- $\beta$-lactam (holomycin, $\beta$ lactamase inhibitory protein and a tunicamycin-related antibiotic) antibiotics $[24,46-54]$. However, CA is currently the most important specialized metabolite produced by $S$. clavuligerus considering its clinical and industrial relevance.

CA is usually produced in submerged cultivation of S. clavuligerus, either wild type or engineered strains. Several operation modes and media compositions have been explored aimed to increase the characteristic low titters of the wild type strain, as Ser et al. [55] reviewed recently. Such strategies might also enhance the CA titers of engineered strains in submerged cultivation. As previously mentioned, glycerol is the most common carbon source used in CA production. When comparing the CA production using glycerol and starch as carbon sources, glycerol promotes CA titers up to 5-fold the observed in cultivations with starch as carbon source [56,57]. Nevertheless, substrate inhibition can occur at glycerol concentrations higher than $50 \mathrm{~g} \cdot \mathrm{L}^{-1}$ [56]. As glycerol acts as the C-3 precursor, the biosynthesis of CA is enhanced by amino acid supplementation [42,58] and rich nitrogen sources like soy protein and soy flour $[56,57]$ that provide abundant $C-5$ precursors through the urea cycle. Conversely, the use of dextrose or starch promote the secretion of Cephamycin C [57,59]. In a media screening study, Da Silva et al. [60] observed the highest CA production $\left(0.437 \mathrm{~g} \cdot \mathrm{L}^{-1}\right)$ with the media having glycerol as the main carbon source and isolated soy protein, while the amino acid supplementation did not enhance the CA productivity. Neto et al. [61] reported CA concentrations in batch, fed batch and continuous cultivations of $0.195,0.404$, and $0.293 \mathrm{~g} \cdot \mathrm{L}^{-1}$, respectively. The highest CA concentrations obtained in bioreactor cultivations using a wild type strain were reported by Teodoro et al. [62]. In that study, batch and fed-batch operation modes were tested using a complex medium prepared with glycerol, malt, and yeast extracts, peptone and trace elements. Batch cultivations yielded $0.430-0.530 \mathrm{~g} \cdot \mathrm{L}^{-1}$ of CA while fed-batch cultivations with ornithine $\left(3.7 \mathrm{~g} \cdot \mathrm{L}^{-1}\right)$ led to a CA concentration of $1.560 \mathrm{~g} \cdot \mathrm{L}^{-1}[62,63]$. A complex culture medium provides important amounts of free or hydrolyzed amino acids, which act not only as nitrogen sources, but also as secondary carbon sources. Complex nitrogen sources, such as those containing soy protein, favor considerably the CA accumulation in contrast to the chemically defined media [56]. The use of complex media with vegetable oils supplementation (olive, cotton, palm, and corn) as secondary carbon sources may enhance the CA production up to 2 -fold when compared to glycerol as a supplement [64-66]. However, the use of complex media leads to denser and more viscous fermentation broths due to the high concentration of suspended solids. Those factors may affect the mass transfer in the bioreactor and the downstream CA separation. Phosphate has a potential repressive effect on CA production; thus, culture media are commonly designed as phosphate-limited [6,42,55]. In this regard, Saudagar and Singhal [58] found a CA biosynthesis repression when increasing the phosphate concentration in the media over $100 \mathrm{mmol} . \mathrm{L}^{-1}$. The studies indicated that CA accumulation is favored in the fed-batch operation under controlled conditions of $\mathrm{pH}$, aeration, and stirring. Those conditions are more easily controllable in stirred tank bioreactors (STR) although the CA production studies are not restricted only to this configuration.

Other factors apart from culture media could affect the CA accumulation in submerged cultures of $S$. clavuligerus. The CA molecule shows high susceptibility to temperature and ionic strength in aqueous solutions, compromising the CA titers during the cultivation $[67,68]$. The $\mathrm{pH}$ conditions seem to affect $\mathrm{CA}$ yield, possibly more linked to molecule degradation than biosynthesis inhibition [69]. The highest concentration of CA has been reported at neutral or slightly acidic $\mathrm{pH}$ conditions (6.8), regardless of the substrates used in the cultivations [55]. A recent report showed that STR cultures of S. clavuligerus subjected to acid stresses ( $\mathrm{pH}$ reduction from 6.8 to 6.3 at a rate of $0.1 \mathrm{pH}$ every $6 \mathrm{~h}$ ) may lead to higher global yields $\left(\mathrm{Y}_{\mathrm{CA} / \mathrm{X}}=0.851 \mathrm{~g}_{\mathrm{CA}} \cdot \mathrm{g}_{\mathrm{x}}{ }^{-1}\right)$ [70]. Low temperatures favor the 
molecule stability; in this regard, higher titers have been reported during operating fermentations at $20^{\circ} \mathrm{C}$ but the growth rate at such temperature is lower than that observed at $28{ }^{\circ} \mathrm{C}[70,71]$. In addition, it has been found that both bacterial morphology in dispersed secondary mycelium and a high density spore suspension inoculum (with concentration $\geq 5 \%$ ) significantly improve CA biosynthesis [72-74].

Regarding the operational variables associated to fermentative processes in Streptomyces species, the nutritional effects have been more studied than the effects of hydrodynamic conditions and reactor geometry [75]. The conventional bioprocesses with Streptomyces strains are generally carried out in STRs, as this traditional geometry has been proven to be reliable as it assures good mixing, mass, and heat transfer rates [76]. Novel impeller geometries for STR have been studied as feasible alternatives for improving the oxygen dissolution and nutrient dispersion during the fermentative process [77]. Few studies involving the hydrodynamic patterns of reactors and its impact on growth, morphology, and mass transfer in Streptomyces cultures have been performed. Such studies are required for a more precise description of antibiotics biosynthesis in bioreactors [75]. The reactor geometry, impeller configuration, and velocity of mixing may impact the oxygen availability on the system; it has been demonstrated that higher mixing velocities and turbulence gives better volumetric oxygen mass transfer coefficients $\left(k_{L a}\right)$, promoting higher specific growth rates $[76,78]$. The reactor design must be focused on balancing mass and heat transfer with shear rates, as the latter can cause hydrodynamic stress on cells, affecting their growth and productivity. In this direction, the novel single-use technologies can offer some advantages, in addition to the better sterility conditions attained in this kind of reactors [75].

In the operation of bioreactors, the agitation rate is related not only with the dissolved oxygen and mass transfer conditions, but also with the shear conditions. The shear forces may affect the broth rheology and transport of nutrients as well as the growth rate and morphology expression on Streptomyces species [79,80]. In the case of S. clavuligerus, agitation and aeration are also considered as factors potentially affecting the CA production. An increase of $50 \%$ in oxygen transfer in shake flask cultures increased the CA production 2-fold [81]. Regarding the bioreactor operation, Rosa et al. [82] found that intense agitation rates, i.e., $800-1000 \mathrm{rpm}$, favored CA accumulation in STRs. The $k_{\mathrm{La}}$ observed in airlift reactors, operated in the range from 3 to $5 \mathrm{vvm}$, are rather comparable to those arising in STRs operating in the range of 600 to $1000 \mathrm{rpm}$; both conditions promote CA accumulation. An analysis of the $S$. clavuligerus response to shear stress conditions showed that high shear forces (up to $7.5 \mathrm{~Pa} . \mathrm{s}$ ) increase the growth rate, mycelial thinning, and CA production, in comparison with cultivations at low shear forces (<1 Pa.s) [79]. Moreover, the mycelial diameter increased 57\% under low shear forces when compared to the morphology at high shear stress $(1.44 \mu \mathrm{m})$; suggesting that CA productivity might be affected by the surface-volume ratio, and consequently by the transport rate of nutrients, oxygen, and product release [79]. In summary, high CA concentrations are attained under adequate provision of $\mathrm{C}-3$ and $\mathrm{C}-5$ precursors that increase the carbon flux towards the biosynthetic pathway under phosphate limitation, while maintaining slightly acidic conditions, controlled temperature, high shear rates, and aeration. Such conditions promote both high biomass production and high CA secretion. Rich media are preferred due to their low cost, availability, and high amino acids content, but a proper $\mathrm{C} / \mathrm{N}$ balance must be maintained along with the phosphate restriction; otherwise, low CA titers could be obtained.

CA chemical synthesis has been also explored as an alternative production method. In this regard, at least two different ways for the synthesis of CA have been reported by using diester and diene compounds $[83,84]$. Nevertheless, the mentioned approaches yield low concentrations of racemic mixtures of CA methyl esters. The products and yields of CA organic synthesis imply more complex and costly separation procedures than in case of the bioprocess. Thus, CA production via submerged cultivation with S. clavuligerus has been selected by the pharmaceutical industry as the more profitable alternative, given the stereochemical selectivity of the biochemical pathway. Likewise, research has focused on solving the key issues in the bioprocess instead of the chemical synthesis, namely, 
the low productivity of the strain, the susceptibility to hydrolysis, and the efficiency of the separation/concentration processes.

\section{Regulation of the CA Production in S. clavuligerus}

Successful secondary metabolite biosynthesis by the Streptomyces genus undergoes complex regulation at many levels, involving transcriptional regulators (pleiotropic regulators and pathway-specific regulators), sigma-factors, and small non-coding RNAs [85]. Therefore, the system-level understanding of the complex regulatory interactions and signaling pathways may lead to novel improvement strategies in the CA production.

Usually, antibiotic biosynthetic clusters are regulated by two types of transcriptional regulators: pathway-specific regulators (PSRs) and pleiotropic regulators [86]. At a lower level, PSRs are located inside the antibiotic biosynthetic cluster and these proteins can bind directly to the promoters of genes in the same biosynthetic pathway $[87,88]$. Similarly, at the top level, global regulators are known to control the production of antibiotics in the Streptomyces genus $[87,88]$.

The claR is a PSR that belongs to the LysR family and triggers the late genes (cyp, $o p p A 1$, and cad) of the CA biosynthetic pathway, specifically those participating in the reactions of CA and clavaminic acid biosynthesis [85,89]. Furthermore, the $c c a R$ is a PSR located in the adjacency of the cephamycin $C$ cluster, and triggers the synthesis of both CA and cephamycin C. The last compound is induced by the ccaR through the regulation of the early genes cas $2, b l s$, pah, and orf2 $[24,85,90]$. The evidence suggests that both ccaR and claR form a regulatory system that controls the CA biosynthesis [91]. Recently, by means of a comparative transcriptomic analysis, Pinilla and colleagues [92] identified that CA cluster genes were up regulated, including both $c c a R$ and claR, when S. clavuligerus was cultured in complex media.

As the CA titers in cultivations using the wild type strain are still low, engineered strains of $S$. clavuligerus perturbing these regulators have posed as attractive alternatives for improving the CA production. Pérez-Llarena and co-workers [93] found that a deletion mutant of $c c a R$ is unable to synthesize CA and cephamycin C; besides, an amplification of this gene led to 2-3-fold rise in the CA and cephamycin $\mathrm{C}$ biosynthesis. Furthermore, Alexander and Jensen [94] investigated the role of the CcaR protein in the cephamycin $\mathrm{C}$ gene cluster in S. clavuligerus. The ccaR gene was also considered as essential in the synthesis of CA, cephamycin C, and non-CA clavams [94]. The authors also concluded that the lack of cephamycin $C$ production in ccaR mutants was mainly due to the absence of some enzymes in the early and middle steps in the cephamycin $C$ pathway. PérezRedondo et al. [89] observed that high replication of the claR gene in multicopy plasmids led to 3-fold and 5-6-fold increases in the CA and alanyclavam production, respectively, with a consequent reduction of cephamycin $\mathrm{C}$ production.

Furthermore, Kizildoğan and co-workers [95] engineered a CA-overproducer (S. clavuligerus IDG3) strain yielding CA titers up to $6.690 \mathrm{~g} \cdot \mathrm{L}^{-1}$. In that study, the authors overexpressed clavaminic acid synthase (cas2 gene) and the genes claR and ccaR independently using diverse promoters that were introduced into the industrial strain S. clavuligerus DEPA. The overexpression of $c c a R$ under the control of a $g l p F$ promoter, introduced into S. clavuligerus DEPA, led to 25.9-fold CA production compared to its vector control. Qin et al. [96] fused the neo gene (a kanamycin resistance gene without promoters) with claR, generating the $S$. clavuligerus (NEO) strain able to produce CA titers up to $3.260 \mathrm{~g} \cdot \mathrm{L}^{-1}$. Subsequently, and after a series of treatments and screening, the authors obtained a new engineered strain (M3-19), which produced up to $4.330 \mathrm{~g} \cdot \mathrm{L}^{-1}$ of CA, an increase of $33.8 \%$ compared to the NEO strain. Recently, Cho et al. [97] overexpressed the genes ccaR, cas1, and claR in the mutant strain S. clavuligerus OR. Upregulation of cas1 improved the CA yield in S. clavuligerus OR, leading to CA concentration of $4.95 \mathrm{~g} \cdot \mathrm{L}^{-1}$, approximately $25 \%$ more compared to the control S. clavuligerus OR. Additionally, the overexpression of claR and $c c a R$ in the same mutant strain increased the CA accumulation up to $5.66 \mathrm{~g} \cdot \mathrm{L}^{-1}$ in shake flask cultivations. Nevertheless, a co-expression of claR, ccaR, and cas1 did not improve the 
CA titers. Batch cultivation of S. clavuligerus OR with overexpressed ccaR and claR in a $7 \mathrm{~L}$ bioreactor accumulated $6.010 \mathrm{~g} \cdot \mathrm{L}^{-1}$ of CA.

In addition to $c l a R$ and $c c a R$, the regulatory pathway that controls CA production contains other important regulators. The CcaR formation is modulated by other regulatory proteins like AreB and ScaR, both $\gamma$-butyrolactone receptor proteins. AreB is an autoregulation binding protein that belongs to the transcriptional regulators family termed IclR and is located upstream of the ccaR gene; it binds to the sequences (ARE, autoregulatory elements) located upstream of target genes [24]. Santamarta and colleagues [98] found that AreB modulates the assimilation and biosynthesis of lysine. The mutant $\triangle a r e B$ of $S$. clavuligerus induces an increase in CA and Cephamycin C levels; highlighting an important role of areB in connecting secondary and primary metabolism. ScaR (Brp, $\gamma$-butyrolactone receptor protein) is an autoregulator induced by $\gamma$-butyrolactone that controls directly ccaR and indirectly claR via the AdpA signaling pathway. The AdpA transcriptional regulator is downregulated by ScaR (in scar mutants adpA is upregulated), and regulates positively the CA production, as it was demonstrated by the mutant $\triangle a d p A$ strain [99].

In the Streptomyces genus, an important type of global regulators is the two-component system (TCS), which usually regulates both antibiotic production and morphological development. The TCS consists of a histidine kinase bound to the extracellular membrane, which senses external perturbations, and a response regulator, which triggers the transcription of target genes by undergoing a signal transduction pathway $[100,101]$. Fu and colleagues $[102,103]$ found that CagRS is a pleiotropic regulatory TCS that has a positive effect on CA production. Transcriptome analysis of the mutant $\Delta c a g R S$ versus wild type shown that CagRS TCS induces the up regulation of the CA biosynthetic gene pathway and also that CagRS positively regulates glyceraldehyde 3-phosphate but negatively regulates arginine biosynthesis [102].

Similarly, other TCS have been identified for S. clavuligerus. Kwong and colleagues [104] found that the transcription of the transcriptional activator com $7 p$ is controlled by a TCS formed by snk and res2. Mutants of res2 and snk were incapable to synthesize metabolites of the 5S clavams pathway [104]. Another important two-component regulatory system is associated with the phosphate (Pho) regulon, the unique known regulatory mechanism in response to phosphate starvation in bacteria [105]. The hypothesis of a Pho regulon present in S. clavuligerus is supported by the high production of CA under phosphate limitations. Salehghamari et al. [106] predicted the existence of this regulon by the identification of $\mathrm{PHO}$ binding sequences in promoter regions of 31 genes of $S$. clavuligerus.

Likewise, other TCS is the AfsK-AfsR serine/threonine kinase system, which induces the production of secondary metabolism gene clusters in S. lividans and S. coelicolor [107]. The $a s f R-p$ is a homologue of $a s f R$, the substrate of AfsK from the AfsK-AfsR. Paraluji and colleagues [108] demonstrated the potential of this pleiotropic regulation by overexpressing asfR- $p$ in distinct Streptomyces bacteria, including S. clavuligerus, which showed a CA production of $0.065 \mathrm{~g} \cdot \mathrm{L}^{-1}$.

Recently, it was found that CepRS (cephamicyn regulator/sensor) is a TCS regulator with a key role in the cephamycin C biosynthesis [109]. Although this TCS did not affect the production of $\mathrm{CA}$, this mutant strain $(\triangle c e p R S)$ in combination with the overexpression of CA specific regulators may be an interesting alternative for improving CA production.

Expression of secondary metabolism in bacteria is also regulated by sigma factors. Sigma factors are proteins that recognize the RNA polymerase and allow the proper union to the gene promoter, leading to the synthesis of a mRNA molecule [110]. Similarly, an anti-sigma factor inhibits the transcription, as they will bind to the RNA polymerase, thus preventing that sigma factors from mediating the binding to the promoter site [110].

The sigma factor gene, orf21, is located downstream of the CA biosynthesis cluster in S. clavuligerus. Jnawali et al. [111] disrupted and overexpressed this gene in a S. clavuligerus NRRL3585 and found a reduction 10-15\% in the levels of CA in the $\triangle$ orf 21 mutant; while in the same conditions, overexpression of orf 21 exhibited a 1.45-fold increase in CA yields during fermentation. S. clavuligerus also encodes $b l d G$, an anti-anti-sigma factor, which controls 
genes (regulated by sigma factors) involved in morphological development and secondary metabolite biosynthesis. Bignell and colleagues [90] found that bldG regulates CA biosynthesis by modulating the expression of $c c a R$, and recently, this regulator has been associated with a direct regulatory role in the tunicamycin biosynthesis [112].

The stringent response is a stress response phenomenon that occurs in bacteria under substrate starvation, e.g., amino acid deprivation, iron restriction, and other stringent conditions [113]. This stress mechanism involves the RelA/SpoT protein system (ppGpp synthase (RelA) and (p)ppGpp synthase/hydrolase (SpoT)), which mediates the synthesis of phosphorylated nucleotides like (p)ppGpp [24,85]. This nucleotide exerts a regulatory role in ribosomal genes via RNA Polymerase binding it is also involved in the morphological differentiation of S. clavuligerus [114]. Likewise, a relA mutant of S. clavuligerus showed reduced capability to yield both CA and cephamycin C [115].

In addition to the strain design based on overexpression or mutation of regulatory genes, some research efforts have been focused in targeting the primary metabolism. $\mathrm{Li}$ and Townsend [116] doubled CA production by deleting the gap1 gene in a mutant of S. clavuligerus NRRL3585, increasing the glyceraldehyde 3-phosphate pool for CA biosynthesis. Jnawali et al. [117] used the last approach along with the overexpression of ccaR and claR to create an overproducer engineered strain. Recently, overexpression of lys $A$ in S. clavuligerus NRRL 3585, a gene involved in L-lysine biosynthesis (coding for a diaminopimelic acid decarboxylase), showed improvements in the production of CA, cephamycin $\mathrm{C}$ and tunicamycin.

In this decade, it has been also described engineered strains of $S$. clavuligerus perturbing random genes through mutagenesis techniques. Medema and colleagues [118] engineered an industrial strain (DS48802) through an iterative process of mutagenesis and screening of $S$. clavuligerus ATCC 27064. This mutant strain produced CA levels 100 times more than the wild type. Likewise, an improvement in CA yields using mutagenesis induced by ultraviolet on Streptomyces sp. NRC77 was reported [119]. The authors found a mutant strain after screening (Streptomyces sp. MU-NRC77) that was able to produce $0.272 \mathrm{~g} \cdot \mathrm{L}^{-1}$ of $\mathrm{CA}$ in the production medium, while the addition of $\mathrm{H}_{2} \mathrm{O}_{2}$ and plant charcoal increased the production up to 0.649 and $0.683 \mathrm{~g} \cdot \mathrm{L}^{-1}$, respectively. Recently, CruzHernandez et al. [120] also used UV mutagenesis for enhanced CA titer by S. clavuligerus. The authors obtained mutants of S. clavuligerus ATCC 27064 via UV radiation, and one of them achieved a CA concentration of $0.500 \mathrm{~g} \cdot \mathrm{L}^{-1}$. Although both studies reported an increase of 5.2- and 1.6-fold on CA production compared to wild-type strain, respectively, the titers are too low to be considered in a large-scale process. The summary of studies reporting the highest $C A$ titers using $S$. clavuligerus engineered strains is presented in Table 1.

Table 1. Studies reporting the highest CA production with engineered S. clavuligerus strains.

\begin{tabular}{|c|c|c|c|c|c|}
\hline Strain & Operation Mode & Strain Intervention & Supplement & Titers $\left(g \cdot \mathbf{L}^{-1}\right)$ & Ref. \\
\hline S. clavuligerus IDG3 & Fed-batch & $\begin{array}{c}\text { Overexpression: cas } 2, \\
\text { ccaR, claR }\end{array}$ & Glycerol trioleate & 6.690 & [95] \\
\hline S. clavuligerus M3-19 & Batch & $\begin{array}{l}\text { Reporter gene neo fused } \\
\text { downstream of claR }\end{array}$ & - & 4.330 & [96] \\
\hline S. clavuligerus NEO & Batch & $\begin{array}{l}\text { Reporter gene neo fused } \\
\text { downstream of claR }\end{array}$ & - & 3.260 & [96] \\
\hline $\begin{array}{l}\text { Streptomyces sp. } \\
\text { MU-NRC77 }\end{array}$ & Fed-batch/Batch & UV mutagenesis & $\begin{array}{l}\mathrm{H}_{2} \mathrm{O}_{2} / \text { Activated } \\
\text { animal charcoal }\end{array}$ & $0.649 / 0.683$ & [119] \\
\hline S. clavuligerus 70 & Batch & UV mutagenesis & - & 0.500 & [120] \\
\hline S. clavuligerus OR & Batch & $\begin{array}{l}\text { Random mutagenesis } \\
\text { and cas } 1, c c a R \text { and claR } \\
\text { overexpression }\end{array}$ & - & $\begin{array}{c}5.520(\mathrm{OR} / \mathrm{pCAS} 1) \\
6.010 \text { (OR/pCCAR- } \\
\text { CLAR) }\end{array}$ & [97] \\
\hline
\end{tabular}


Despite $S$. clavuligerus being the strain commonly used in the large-scale process of CA production, there are other CA-producer Streptomyces species, which might be further studied and possibly engineered.

\section{Advances in Systems Level Understanding of the CA Production in S. clavuligerus}

In the recent decade, whole system-level approaches and omics technologies are being developed to explore and understand the existing complex interaction between different biological layers, such as the genome, transcriptome, proteome, and metabolism. A deeper understanding of the BGCs regulation and expression in S. clavuligerus is important to improve the CA production in submerged cultures.

The first draft genome of $S$. clavuligerus was sequenced by two independent research groups in 2010 [121,122]. The genome is composed of a $6.8 \mathrm{Mb}$ chromosome and four linear plasmids named pSCL1 (11 kb), pSCL2 (150 kb), pSCL3 (430 kb), and pSCL4 (1.8 Mb), and a GC $\%$ of 72. The global annotation of this genome refers six rRNA operons, 66 tRNA genes, and 7898 protein-coding genes (5700 in the chromosome). The S. clavuligerus genome contains a plethora of BGCs that includes secondary metabolites like staurosporine, moenomycin, terpenes, pentalenenes, phytoenes, siderophores, lantibiotics, holomycin, cephamycin C, and CA [121]. Specifically, the gene cluster of CA is situated in the chromosome and there exists a paralog gene cluster located in the pSCL4 plasmid codifying for CA and clavam metabolite production. In 2016, the genome of a S. clavuligerus industrial strain (F613-1) was sequenced. The assembly of the genome sequences identified a chromosome and a plasmid. The main differences were reported in the plasmid of F613-1, which contains a smaller number of coding genes compared to the $1.8 \mathrm{Mb}$ megaplasmid of S. clavuligerus ATCC 27064 [123]. The significance of these differences needs further investigations.

Recently, Hwang and colleagues [124] performed a complete systems biology analysis for identifying new regulatory elements and BGCs in S. clavuligerus using new generation high-throughput technologies. In this research, the authors sequenced a high-quality genome of S. clavuligerus ATCC 27064, and it was used as a template to integrate the ribosome profiling and differential RNA-seq data. In that study, 58 potential BGCs were identified, including CA, $5 \mathrm{~S}$ clavams, holomycin, tunicamycin, and 14 terpene type and 12 polyketides type BGCs. Furthermore, 2659 Transcription Start Sites (TSSs) and regulatory elements in the whole genome were identified. The same study reported that COG functional categories like coenzymes, secondary metabolites, inorganic ions, carbohydrate, and amino acid metabolism exhibited high differential expression levels during distinct growth phases while categories like signal transduction, replication, and cell division exhibited constitutive expression during all growth phases. Similarly, Lee and colleagues presented a high-quality genome and developed a data mining analysis for identifying secondary metabolite BGCs in thirty Streptomyces strains, including improvements in previous genome annotations and the identification of 43 BGCs in S. clavuligerus [125]. Similar approaches were performed for other bacteria of the Streptomyces genus [126].

Although the analysis and study of the transcriptome in S. clavuligerus have been relevant for identifying regulatory elements in the genome, they are also useful for understanding the up- or downregulation of metabolic pathways involved in CA production at specific nutritional conditions. In 2011, Medema et al. [118] developed the first comparative transcriptome analysis of a S. clavuligerus industrial strain (engineered by random mutagenesis) versus a wild type strain. They captured transcript changes in central carbon and secondary metabolism, specifically, upregulation of ammonium and phosphate transporters, and glutamine and glutamate synthase genes. In 2014, Álvarez-Álvarez and co-workers [127] developed a comparative transcriptomic analysis between a ccaR-deleted mutant and the wild type strain S. clavuligerus ATCC 27064. The authors observed that cephamycin C and CA biosynthetic genes were negatively regulated in the ccaR mutant, a gene expression pattern previously identified [128]. Likewise, blip and blp, two genes encoding $\beta$-lactamase inhibitory proteins, were downregulated. The most interesting metabolic phenotype was the overexpression of all the genes involved in holomycin biosyn- 
thesis, in agreement with previous studies reporting high holomycin production in ccaR mutants [129]. Similar results were found in a claR mutant; genes like hlmI and hlmH were upregulated during the entire fermentation [130]. In contrast, poor regulation of genes in the initial and late steps of CA biosynthesis, and thus no CA production were detected [130]. Recently, the oppA2 gene (oligopeptide binding protein permease) was identified as essential for CA production [131]. Transcriptional analysis of oppA2 mutant compared to the wild type strain also allowed identifying upregulation of holomycin genes and no significant expression of cephamycin $C$ and CA biosynthesis clusters. However, the most interesting result was that oppA2 mutant secreted $\mathrm{N}$-acetylglycyl-clavaminic acid, an intermediate of the CA biosynthesis. The evidence suggests that this peptide probably is bound to the OppA2 protein forming a multi-enzymatic complex in the final stages of CA biosynthesis [131]. A proteomic study of the same oppA2 mutant identified high level abundance of rhodanese-like enzyme ( $r h l A$, thiosulfate sulfur transferase) [132]. Deletion of this gene showed impairment of holomycin (90\%) and lower CA and cephamycin C production.

Overexpression of non-native transcriptional regulators into S. clavuligerus could become an interesting approach for improving antibiotic production in the Streptomyces genus. In 2019, Martínez-Burgos et al. [133] overexpressed pimM in S. clavuligerus ATCC 27064, a PAS-LuxR activator of the pimaricin biosynthetic cluster present in Streptomyces nataliensis. A comparative transcriptome analysis indicated that overexpression of pimM triggers the production of both CA and cephamycin C, by affecting the expression of secondary metabolite gene clusters like SMC10, SMC13, and SMCp5, including the upregulation of CA biosynthesis and cephamycin C clusters [133]. Untargeted metabolic profiling of the pimM expression identified antifungal compounds similar to tunicamycin.

A proteomic analysis comparing the wild type strain of S. clavuligerus and two mutants lacking the global regulators $b l d A$ and $b l d G$ (bldA regulates the morphological development and bldg regulates $C A$ and cephamycin $C$ production) was conducted [134]. The authors showed that the $b l d A$ mutant reduced the CA production by $80 \%$, while in the bldG mutant the CA levels were not detected compared to the wild type [134]. The bldG mutant exhibited a large percentage of differentially expressed proteins; those classified in functional categories like metabolism, cellular processes, regulation, translation, and energetics. When compared to the wild type, the bldA mutant showed a lower percentage of differential expressed proteins in the same categories [134]. The most interesting result of this wholecell proteomic analysis was the detection of protein regulators (such as BldG, RshA, SigH, BldD, AdsA, BldC, AdpA, AfsA, AbsB, DraK, AfsK, and PhoP) involved in the regulatory cascade of CA biosynthesis [134]. Another whole-cell proteome analysis was developed by Ünsaldı et al. (2017). They performed a proteome-wide study in an industrial CA overproducer strain (S. clavuligerus DEPA) [135]. In that case, three CA biosynthetic enzymes were overexpressed: (i) $N^{2}$-(2-carboxyethyl)-arginine synthase (CEAS2), (ii) clavaldehyde dehydrogenase (Car) (also known as clavulanic acid dehydrogenase (CAD)), and (iii) carboxyethyl-arginine $\beta$-lactam synthase (BLS2). The authors identified 33 different ORFs that were underexpressed and $60 \mathrm{ORFs}$ that were overexpressed. A decrease on the expression level of genes associated with methionine biosynthesis and some enzymes of the glycolytic pathway were observed and identified as the main causes for the CA overproduction in the S. clavuligerus DEPA strain $[95,135]$.

Most previous studies have, at least, one point in common: the genes manipulated are involved, or related, to the clavam pathway. However, the evidence suggests that investigations should not target only the clavam pathway to enhance CA production. Despite the recent advances regarding the cephamycin C and CA gene cluster in S. clavuligerus, further research on those pathways and other regulatory pathways must be conducted in order to decipher the complex metabolism of S. clavuligerus. In this regard, ChIP-Seq, transcriptomic, and proteomic analysis may contribute to elucidate the mechanisms involved in the "late" steps, especially the genes responsible for the inversion of (3S, 5S)-clavaminic acid into $(3 \mathrm{R}, 5 \mathrm{R})-\mathrm{CA}$, and their regulation and connection with CA biosynthesis. Addi- 
tionally, more studies focused on the $5 \mathrm{~S}$ clavam branch are required. For instance, studies related with com6P (encode a putative aminotransferase responsible for the first reaction of the $5 \mathrm{~S}$ clavam pathway) and the carbon flux control downstream this bifurcation point, as a strategy to enhance the CA production [136].

\section{Genome-Scale Modeling: A Suitable Platform for Improving CA Production}

As previously described, the development of high-throughput techniques has allowed to measure and quantify a high number of cellular molecular constituents from the different biological levels (genome, RNAs, proteins, metabolites, etc.). The analysis of omics data is giving lights about the interrelated or individual relationship of biological levels (genes, proteins, regulators, and metabolites) and the production of specialized metabolites [137-140]. However, the integration of multiple omics datasets for analyzing the interplay between biological levels is still a challenging task [141-146]. Most of the proposed methodologies for multi-omics data integration have been focused on the socalled element-based approaches (correlation, clustering, and multivariate analysis) [147]. These are useful to define correlations or groups in a particular biological level and a specific condition, but not to reveal the molecular mechanisms associated with a specific cell phenotype. However, the use of mathematical-based approaches considering system components, network interaction, and physicochemical properties of the cell, poses as a suitable alternative for multi-omics data integration. Such approaches can be used to infer the interplay between biological levels through the identification of mechanisms governing the cell phenotype.

A mathematical-based approach that allows studying the metabolic fluxes and phenotypes of a cell under a plethora of nutritional/genetic/regulatory perturbations is the genome-scale metabolic modeling (GEMs) $[148,149]$. This mathematical platform along with the integration of omics data (genomics, transcriptomics, proteomics, metabolomics, etc.) has demonstrated usefulness in guiding experimental efforts and elucidating mechanisms affecting cell phenotypes in many different cell types [150-156].

Usually, GEMs contain all the biochemical knowledge of a cell through the formulation of mass balances per metabolites and the existing association between genes, proteins/enzymes, and reactions [157]. The stationary mass balance is the simplest mathematical formulation allowing computing carbon fluxes under specific nutritional conditions. The mass balances are represented in a stoichiometric matrix multiplied by an unknown vector of reaction velocities (reaction fluxes), configuring a linear programming problem with an objective function based on some evolution criteria like the maximization of growth or energy production yield [158]. Under this consideration the in silico cells use most of the available nutrients to grow as expected to occur under the appropriated biological conditions [159]. This approach is vastly known as Flux Balance Analysis (FBA) and it is widely used for studying cell metabolism in many areas of research [160,161].

Application and use of genome-scale metabolic modeling of Streptomyces bacteria is currently an active field of study $[138,145,162-164]$, including the modeling of S. clavuligerus metabolism (Figure 4) $[19,43,122,165,166]$.

In 2000, Kirk and colleagues [167] published the first reconstructed metabolic model of $S$. clavuligerus; a mathematical model limited to central carbon metabolism, amino acid biosynthesis, anaplerotic reactions, urea cycle, and the specific pathway of CA biosynthesis. This model was used to explore the metabolic adaptation strategies of $S$. clavuligerus during a chemostat culture under phosphate, carbon and nitrogen limitations. The researchers found that anaplerotic metabolism decreases under carbon limitation, limiting the use of alpha-keto glutarate from the TCA cycle to synthesize C5 precursors. Conversely, under phosphate limited conditions the flux through C5 precursors was favored, increasing the CA production. 


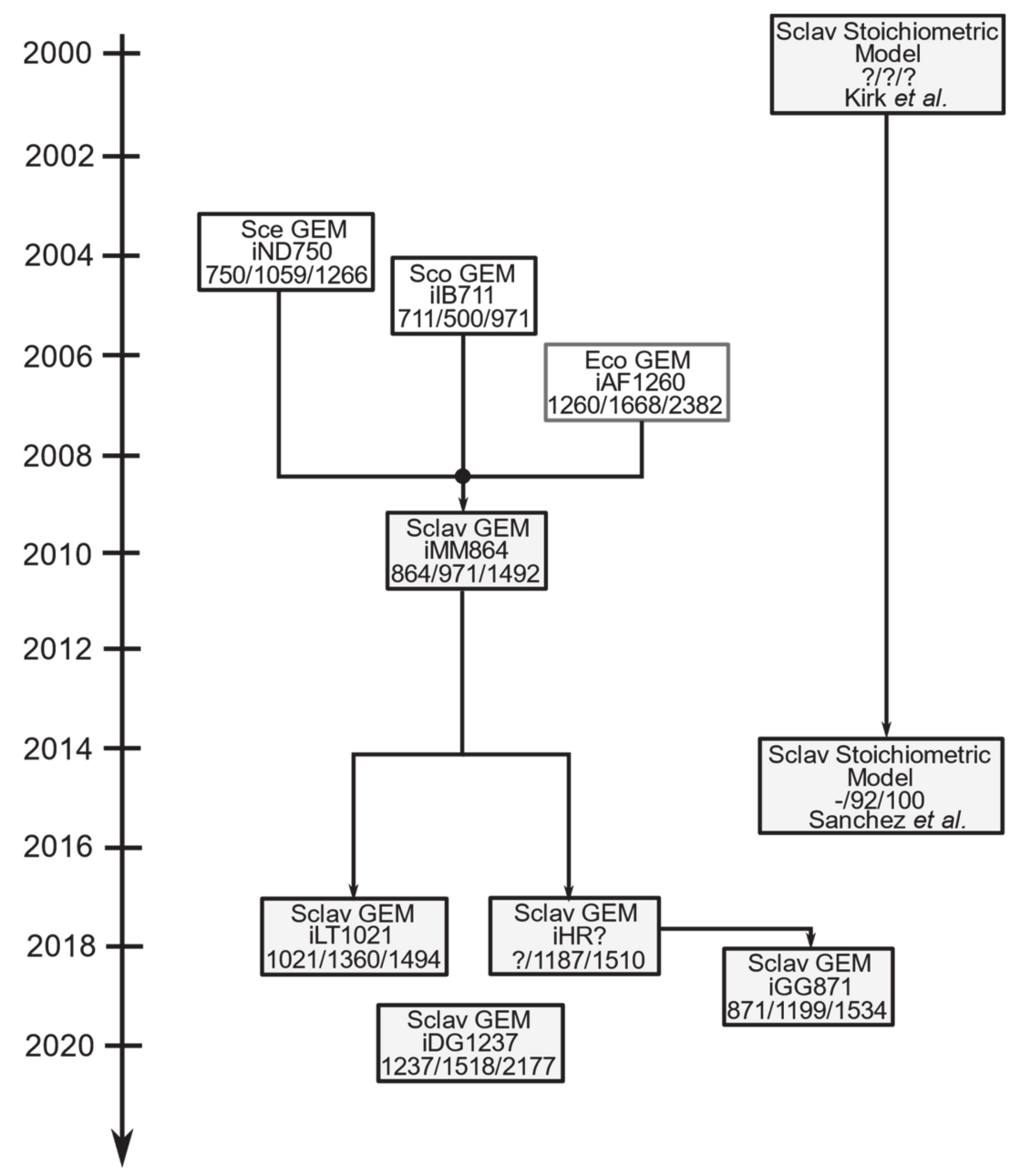

Figure 4. The evolution of S. clavuligerus metabolic models. Species abbreviations are Sclav: Streptomyces clavuligerus, Sco: Streptomyces coelicolor, Sce: Saccharomyces cerevisiae, Eco: Escherichia coli. Similarly, number of genes, metabolites, and reactions were included after a/symbol, respectively.

In 2010, Medema and colleagues [122] used the annotation information of S. clavuligerus ATCC 27064 genome in the reconstruction of the first genome-scale metabolic model of S. clavuligerus (iMM864). This model encompasses 1492 reactions, 971 metabolites, and 864 genes; it was used to simulate growth on different nitrogen and carbon sources and evaluate essentiality of the $1.8 \mathrm{Mb}$ megaplasmid identified in S. clavuligerus ATCC 27064. Later, the same authors demonstrated that the FBA predicts the metabolic fluxes through the biosynthetic precursors of $\mathrm{CA}$; in line with the gene expression data of the S. clavuligerus overproducer strains (claR/ccaR overexpression and $\triangle$ gap1) [118].

In 2015, a stoichiometric model of S. clavuligerus (containing 100 reactions and 91 metabolites) expanded from the first model was used to explore the effect of nutrients (carbon, nitrogen, and phosphate) and oxygen limitations on CA production [44,167]. The authors found that maximization of ATP yield was the best objective function as it was the most suitable function for predicting CA production. Likewise, they found that during the phosphate limitation, CA production was favored when glutamate flux and the precursors of the urea cycle increased.

In 2018, two model updates of iMM864 were published. First, the iLT1021 GEM containing 1494 reactions, 1360 metabolites, and 1021 genes, using ATP yield as the best objective function to represent $S$. clavuligerus cultivated in chemostat mode, while growth rate was used as the objective function for the batch cultures [165]. The authors identified the NAD+ synthase, glyK, and $i d h$ genes as the best metabolic targets for improving the CA production. In 2018, Ramirez-Malule and colleagues [43] also improved the iMM864 GEM 
by including gene-reaction associations and gap-filling curation. This model was used to characterize the TCA strategies used by S. clavuligerus at four different growth conditions associated with CA production [43]. The authors found that CA biosynthesis correlates positively with accumulation of oxaloacetate, succinate, and acetate, while it correlates negatively with accumulation of malate at different feeding conditions in continuous cultures [43]. Additionally, FBA-fluxes inferred from experimental data predicted that the phosphoenolpyruvate carboxylase activation triggers CA production. In contrast, the activation of the glyoxylate shunt (by isocitrate lyase) matched with carbon limitation conditions and a negative effect on CA titers [43].

The last model was updated and curated in 2019, containing 1534 reactions, 1199 metabolites and 871 genes [166]. Although this model was not validated with experimental data, it explored 18 objective functions and metabolic phenotypes of $S$. clavuligerus during production of CA and Cephamycin C.

Finally, in 2020, a new and independent reconstruction was published [19]. The topologically and thermodynamically curated iDG1237 GEM encompasses 2177 reactions, 1518 metabolites, and 1237 genes. This model was validated with experimental data and used to get insights about the metabolic reprograming strategies of $S$. clavuligerus under high and low shear stress conditions (intracellular nutrient availability). The authors showed that during phosphate-limited and low shear stress conditions the CA production halved due to the existence of overflow metabolism coincident with accumulation of TCA intermediates. These evidences suggest that GEMs constitute valuable platforms for exploring the metabolism of $S$. clavuligerus under different experimental and nutritional conditions. We invite the $S$. clavuligerus community to use these models along with multi-omics datasets for getting further insights about the regulatory links between genes, proteins and metabolism in order to improve CA production at the industrial level.

\section{Downstream Processing of CA}

Due to its low molecular weight and its instability in aqueous solution at room temperature diverse processes for CA separation and purification have been employed, e.g., filtration or centrifugation, liquid-liquid extraction, and ion exchange chromatography. In addition to the characteristic low productivity of the bioprocess, the product yield is also compromised by the degradation of CA in aqueous phases and the efficiency of the separation steps required for the obtention of potassium clavulanate (the stable commercial form). Several authors have confirmed the degradation of CA in fermentation broths $[67,69,168-170]$, synthetic buffer $[68,171,172]$, and pure water [173-175]. The CA secreted by $S$. clavuligerus exhibits a high initial reaction rate $(\sim 5 \mathrm{~h})$ in aqueous solution (e.g., fermentation broths) followed by a slower degradation rate in the next hours $[168,169]$. Degradation of CA is considered consequence of susceptibility to nucleophilic attacks at specific points. This acts as a hydrolytic mechanism in two steps: an equilibrium reaction leading to an active intermediate and an irreversible reaction of this intermediate with another CA molecule, thus leading to the degradation product $[67,176,177]$. As consequence, CA increases its own degradation rate when increasing concentration in the fermentation broth $[68,176]$. Usually, CA purification starts (after cultivation process) with the removal of the cells from cultivation broth either by centrifugation or filtration. Then, the antibiotic is separated through adsorption, liquid extraction, or both, followed by the clavulanate salt precipitation. Nevertheless, the observed instability of CA makes the efficient recovery necessary to improve the profitability of the CA production process at reduced operation costs.

One of the most explored alternatives for CA recovery from fermentation broths is the adsorption with selective materials such as ion exchange resins, activated carbon, hydrotalcites, zeolites, and double-layer hydroxides. This technique allows the biomolecules to be selectively adsorbed in solid materials while minimizing the degradation of the product. Forte et al. $[178,179]$ studied the CA recovery from aqueous solutions by using natural and synthetic zeolites, namely, faujasite-type NaX zeolite (13X) and clinoptilolite- 
mordenite zeolite (NZ) and their modified cationic forms $\left(\mathrm{K}^{+}, \mathrm{Na}^{+}, \mathrm{Ca}^{2+}, \mathrm{Ba}^{2+}, \mathrm{Mg}^{2+}, \mathrm{Sr}^{2+}\right)$, with aperture diameters ranging 0.062 and $0.150 \mathrm{~mm}$. The 13X-Na zeolite showed the best CA retention (17.4\%) in the equilibrium at a zeolite/liquid ratio of $0.5 \mathrm{mg} . \mathrm{g}^{-1}$ [178]. Higher retention levels have been obtained in separations with quaternary ammonium anionic exchange resins, such as Amberlite IRA 400 and Q Sepharose XL. In this regard, Barboza et al. [180,181] studied the temperature effect on CA adsorption and desorption in flask-scale experiments, showing that $\mathrm{CA}$ removal from aqueous solution is very favorable (retention values between 60 and $70 \%$ ) at temperatures ranging from 5 to $10^{\circ} \mathrm{C}$ given the exothermicity of the CA-resin bonding. The desorption process is facilitated by higher temperatures (up to $30^{\circ} \mathrm{C}$ ) than the adsorption, the equilibrium time is almost doubled and the desorption ratio is about $60 \%[180,181]$. Almeida et al. [182] proposed a simultaneous adsorption/desorption system of CA using sequential stirred tanks, allowing the recycling of the fermentation supernatants and hence, increasing the CA adsorption percentages. Absorption operations in packed columns with IRA 400 operating at a flow rate of $0.3 \mathrm{~L} \cdot \mathrm{h}^{-1}$ and $10{ }^{\circ} \mathrm{C}$ were used, followed by desorption with $2 \% \mathrm{NaCl}$ at $30^{\circ} \mathrm{C}$. Even though the absorption in fixed beds have provided good results in terms of separation and concentration, CA degradation may occur within the sites of the ion-exchange resin, reducing the overall yield of the process [183]. The rapid CA degradation in aqueous media has implications on the selection of the separation technology, the shorter the time of CA in aqueous solution, the lower its degradation. Furthermore, the complete CA desorption from the ion exchange matrix doubles the adsorption time, increasing the product losses. The layered double hydroxides (LDHs) have been also explored for CA adsorption from aqueous solutions. LDHs are mixed hydroxides with layers of divalent, trivalent cations, and hydroxyl anions capable of anion exchange [184]. The interlayer domain is constituted by water molecules and anions [184]. When using calcined hydrotalcite $\mathrm{LDHs}$ containing $70 \% \mathrm{MgO}$ in a solidliquid ratio of $15.0 \mathrm{~g} \cdot \mathrm{L}^{-1}$, complete adsorption of CA was observed [184]. CA adsorption into $\mathrm{Zn}_{2} \mathrm{Cr}-\mathrm{NO}_{3}, \mathrm{Zn}_{2} \mathrm{Al}-\mathrm{NO}_{3}$, and $\mathrm{Mg}_{2} \mathrm{Al}-\mathrm{NO}_{3} \mathrm{LDHs}$ was satisfactory, but the best results were observed for the $\mathrm{Zn}_{2} \mathrm{Cr}-\mathrm{NO}_{3} \mathrm{LDH}$ microencapsulated with calcium alginate, showing a purification factor of about 2.3 and CA recovery between 93 and 99\% [185,186].

Aqueous two-phase systems (ATPS) have been also studied for CA separation from fermentation broths. ATPS are formed when two hydrophilic components are mixed in water above a threshold concentration [187]. Two polymers or a polymer and a salt are commonly used. Those systems are convenient for the purification of bioactive compounds due to the high water content (70-90\%) in both phases [187]. The use of ATPS for CA recovery from cultivation broths was first reported by Videira and Barros [188]. The authors used the ATPS of polyethylene glycol (PEG) and potassium phosphate for CA extraction. Under the conditions tested, CA showed high affinity to the PEG-rich (top) phase, yielding recoveries ranging from 90 to $99 \%$ [188]. The subsequent optimization studies confirmed the high recovery ratio of this technique, using PEG with molecular mass of 400 daltons at pH 6.4 and top/bottom phase volume ratios of 42 and 1.3, respectively [189]. Similar results have been observed when using other PEG based ATPS like those formed by PEG/citrate, PEG/polyacrylate and PEG/cholinium chloride [187,190,191]. Furthermore, Silva et al. [192] used ATPS followed by ion-exchange adsorption for CA separation from complex fermentation broths with high amino acids content. The ATPS-Ion exchange system produced CA recoveries of $100 \%$ in both stages, which is higher than the separation reached when using single ion-exchange adsorption. However, the CA degradation rate in ATPS systems remains to be assessed given the susceptibility of CA to hydrolysis via nucleophilic attacks to the carbonyl group [176].

Viana-Marques and co-workers [193] investigated the application of ATPS in the CA extractive fermentation with a variant of $S$. variabilis in the shake flask and bioreactor scales, taking advantage of the high extraction levels attained with this separation strategy. ATPS $25 \%$ PEG $8000 \mathrm{~g} \cdot \mathrm{mol}^{-1}$ and phosphate salts led to CA productivity of $5.3 \mathrm{mg} .(\mathrm{L} \cdot \mathrm{h})^{-1}$ [193]. The CA concentration in the PEG-rich phase was $691 \mathrm{mg} \cdot \mathrm{L}^{-1}$, which was $30 \%$ higher than in the cultivation broth [193]. In the bioreactor scale (950 rpm, $3.5 \mathrm{vvm})$, this strategy 
allowed a maximum CA production of $434 \mathrm{mg} \cdot \mathrm{L}^{-1}$ [194]. The authors emphasized that this technology constitutes a low-cost platform to simultaneously produce and recover CA with high yields. Similarly, Lopes-Costa and Colli-Badino employed extractive fermentation using IRA 400 ion-exchange resin, obtaining a CA recovery of $78 \%$; thus, increasing the cumulative CA concentration in $248 \%$ compared to the control without product removal [195]. The increase of CA productivity when it is adsorbed from the fermentation broth supports the hypothesis that high CA concentration may inhibit the antibiotic biosynthesis.

A different approach considers the use of aqueous two-phase micellar systems (ATPMS). Those are micellar solutions that separate spontaneously in two phases: a micelle-rich phase and a micelle-poor phase, depending on operating conditions $\mathrm{pH}$, ionic strength, and temperature) [196]. An ATPMS employing the surfactant n-decyltetraethylene oxide showed preferential partition of proteins towards the micelle-rich phase, but if a denaturation step is applied prior to extraction, the $52 \%$ of CA is recovered in this phase [196]. ATPMS formed by the non-ionic surfactant Triton X-114 (0.022\%) and an anionic one (1\%) allowed a CA recovery of $86.3 \%$ at $28{ }^{\circ} \mathrm{C}$ [197]. Similarly, ATPMS of dextran sulfate with non-ionic surfactants Triton X-114 or Triton X-100 have been also used for CA purification, yielding CA recoveries of 80 and $50 \%$, respectively [198].

Aqueous CA from fermentation broths or concentrated solutions can also be extracted by simple liquid extraction with organic solvents. The evaluation of organic solvents butyl acetate, ethyl acetate, n-butanol, 2-butanol, and methyl isobutyl ketone showed that CA partition coefficient is related to solvent properties like dielectric constant and species solubility [199]. Although CA distribution coefficients for 2-butanol and n-butanol were found to be higher than for the esters and the methyl-isobutyl ketone; the high solubility of light alcohols in water makes them impractical for further CA precipitation. For extraction purposes is desirable a water-immiscible organic phase, which also reduces the degradation susceptibility of the molecule. Brites and colleagues [199] concluded that ethyl acetate is the best option considering the subsequent precipitation steps required for the formation of clavulanate salts, yielding a CA extraction of $35.6 \%$ with partition coefficient of 0.73 in acidic conditions. Furthermore, organic solvent mixtures containing methyl-ethyl ketone/ethyl acetate and methyl-isobutyl ketone/ethyl acetate allow higher extraction levels of CA from fermentation broths. The equivolumetric mixtures of methylethyl ketone/ethyl acetate and ethyl-isobutyl ketone/ethyl acetate led to extraction yields of 50 and $44.7 \%$, respectively, which is approximately $30 \%$ higher compared to the obtained for single ethyl acetate extraction [200].

As CA is marketed in salt form, the direct precipitation from aqueous solutions, either fermentation broths or concentrated solutions, has been studied as a purification alternative. CA extracted via organic solvents can be precipitated in two steps: (i) reaction of CA with an aliphatic amine to form a stable CA-amine salt and (ii) precipitation with potassium 2-ethyl hexanoate [201]. However, CA can be precipitated directly from the organic solvent by addition of potassium 2-ethyl hexanoate without requiring the formation of a stable intermediate [202]. However, slightly higher yield was observed when the amine intermediate is formed $(72.4 \%)$ compared to the direct precipitation method $(69.5 \%)[201,202]$.

\section{Concluding Remarks}

Genetic modification of genes involved, or related to, the clavam pathway leads to improvement of CA production in S. clavuligerus. This pathway constitutes a key point for engineering CA overproducer strains aimed to the large-scale application. Despite the high number of successful studies involving synthetic biology approaches, alternative bioprocessing strategies, identification of genes related to pathway regulation, metabolic modeling, and downstream processing, novel strategies need to be implemented to pave the way to higher CA productivity in the antibiotics industry. Thus, a multidisciplinary research approach combining microbiology, bioprocess engineering, biochemistry, molecular biology, analytical chemistry, and computational biology would help to unravel the 
intrinsic metabolic complexity of CA biosynthesis. The connection of CA with the reactionsteps in the clavam pathway and its relationship with the biosynthesis and release of other antibiotics like the cephamycins and penicillins should be further studied considering the interaction between the biological layers.

Author Contributions: Conceptualization, H.R.-M.; methodology, V.A.L.-A., D.G.-R., and H.R.-M.; investigation, V.A.L.-A., D.G.-R., and H.R.-M.; resources, H.R.-M.; writing—original draft preparation, V.A.L.-A., D.G.-R., and H.R.-M.; writing-review and editing, H.R.-M.; visualization, V.A.L.-A., D.G.-R., and H.R.-M.; supervision, H.R.-M.; project administration, H.R.-M.; funding acquisition, H.R.-M. All authors have read and agreed to the published version of the manuscript.

Funding: This research was funded by Universidad del Valle C.I. 21108 and the MinCiencias Postdoctoral Fellowship 848-2019 approved with the project: “Desarrollo de un modelo metabólico cinético a escala del genoma que capture eventos de adaptación metabólica en Streptomyces clavuligerus".

Conflicts of Interest: The authors declare no conflict of interest. The funders had no role in the design of the study; in the collection, analyses, or interpretation of data; in the writing of the manuscript; or in the decision to publish the results.

\section{References}

1. Gómez-Ríos, D.; Ramírez-Malule, H. Bibliometric analysis of recent research on multidrug and antibiotics resistance (2017-2018). J. Appl. Pharm. Sci. 2019, 9, 112-116. [CrossRef]

2. Landecker, H. Antibiotic Resistance and the Biology of History. Body Soc. 2016, 22, 19-52. [CrossRef]

3. Davies, J.; Davies, D. Origins and Evolution of Antibiotic Resistance. Microbiol. Mol. Biol. Rev. 2010, 74, 417-433. [CrossRef] [PubMed]

4. Abraham, E.P.; Chain, E. An enzyme from bacteria able to destroy penicillin. Nature 1940, 146, 837. [CrossRef]

5. Bush, K.; Bradford, P.A. $\beta$-Lactams and $\beta$-Lactamase Inhibitors: An Overview. Cold Spring Harb. Perspect. Med. 2016, 6, a025247. [CrossRef] [PubMed]

6. Saudagar, P.S.; Survase, S.A.; Singhal, R.S. Clavulanic acid: A review. Biotechnol. Adv. 2008, 26, 335-351. [CrossRef]

7. Reading, C.; Cole, M. Clavulanic acid: A beta-lactamase-inhiting beta-lactam from Streptomyces clavuligerus. Antimicrob. Agents Chemother. 1977, 11, 852-857. [CrossRef]

8. Huttner, A.; Bielicki, J.; Clements, M.N.; Frimodt-Møller, N.; Muller, A.E.; Paccaud, J.-P.; Mouton, J.W. Oral amoxicillin and amoxicillin-clavulanic acid: Properties, indications and usage. Clin. Microbiol. Infect. 2020. [CrossRef]

9. Mutlu, A. Increasing Clavulanic Acid Production both in Wild Type and Industrial Streptomyces Clavuligerus Strains by Amplification of Positive Regulator claR Gene; Middle East Technical University: Çankaya/Ankara, Turkey, 2012.

10. de Viana Marques, D.A.; Feitosa Machado, S.E.; Santos Ebinuma, V.C.; de Lima Duarte, C.A.; Converti, A.; Porto, A.L.F. Production of $\beta$-Lactamase Inhibitors by Streptomyces Species. Antibiotics 2018, 7, 61. [CrossRef]

11. Nagarajan, R.; Boeck, L.D.; Gorman, M.; Hamill, R.L.; Higgens, C.E.; Hoehn, M.M.; Stark, W.M.; Whitney, J.G. $\beta$-Lactam antibiotics from Streptomyces. J. Am. Chem. Soc. 1971, 93, 2308-2310. [CrossRef]

12. Higgens, C.E.; Kastner, R.E. Streptomyces Clavuligerus sp.nov. a B-Lactam Antibiotic Producer. Int. J. Syst. Bacteriol. 1971, 21, 326-331. [CrossRef]

13. Howarth, T.T.; Brown, A.G.; King, T.J. Clavulanic acid, a novel $\beta$-lactam isolated from Streptomyces clavuligerus; X-ray crystal structure analysis. J. Chem. Soc. Chem. Commun. 1976, 266b-267b. [CrossRef]

14. Clardy, J.; Fischbach, M.A.; Currie, C.R. The natural history of antibiotics. Curr. Biol. 2009, 19, R437-R441. [CrossRef] [PubMed]

15. Watve, M.G.; Tickoo, R.; Jog, M.M.; Bhole, B.D. How many antibiotics are produced by the genus Streptomyces? Arch. Microbiol. 2001, 176, 386-390. [CrossRef] [PubMed]

16. Xu, J.; Zhang, J.; Zhuo, J.; Li, Y.; Tian, Y.; Tan, H. Activation and mechanism of a cryptic oviedomycin gene cluster via the disruption of a global regulatory gene, adpA, in Streptomyces ansochromogenes. J. Biol. Chem. 2017, 292, 19708-19720. [CrossRef]

17. Peng, Q.; Gao, G.; Lü, J.; Long, Q.; Chen, X.; Zhang, F.; Xu, M.; Liu, K.; Wang, Y.; Deng, Z.; et al. Engineered streptomyces lividans strains for optimal identification and expression of cryptic biosynthetic gene clusters. Front. Microbiol. 2018, 9. [CrossRef]

18. Nguyen, H.T.; Pham, V.T.T.; Nguyen, C.T.; Pokhrel, A.R.; Kim, T.S.; Kim, D.H.; Na, K.; Yamaguchi, T.; Sohng, J.K. Exploration of cryptic organic photosensitive compound as Zincphyrin IV in Streptomyces venezuelae ATCC 15439. Appl. Microbiol. Biotechnol. 2020, 104, 713-724. [CrossRef]

19. Gómez-Ríos, D.; López-Agudelo, V.A.; Ramírez-Malule, H.; Neubauer, P.; Junne, S.; Ochoa, S.; Ríos-Estepa, R. A Genome-Scale Insight into the Effect of Shear Stress During the Fed-Batch Production of Clavulanic Acid by Streptomyces Clavuligerus. Microorganisms 2020, 8, 1255. [CrossRef]

20. Esnault, C.; Dulermo, T.; Smirnov, A.; Askora, A.; David, M.; Deniset-Besseau, A.; Holland, I.B.; Virolle, M.J. Strong antibiotic production is correlated with highly active oxidative metabolism in Streptomyces coelicolor M145. Sci. Rep. 2017, 7, 1-10. [CrossRef] 
21. Millan-Oropeza, A.; Henry, C.; Lejeune, C.; David, M.; Virolle, M.-J. Expression of genes of the Pho regulon is altered in Streptomyces coelicolor. Sci. Rep. 2020, 10, 8492. [CrossRef]

22. Cho, H.; Uehara, T.; Bernhardt, T.G. Beta-Lactam Antibiotics Induce a Lethal Malfunctioning of the Bacterial Cell Wall Synthesis Machinery. Cell 2014, 159, 1300-1311. [CrossRef] [PubMed]

23. Virolle, M.-J. A Challenging View: Antibiotics Play a Role in the Regulation of the Energetic Metabolism of the Producing Bacteria. Antibiotics 2020, 9, 83. [CrossRef] [PubMed]

24. Paradkar, A. Clavulanic acid production by Streptomyces clavuligerus: Biogenesis, regulation and strain improvement. J. Antibiot. 2013, 66, 411-420. [CrossRef] [PubMed]

25. Jensen, S.E. Biosynthesis of clavam metabolites. J. Ind. Microbiol. Biotechnol. 2012, 39, 1407-1419. [CrossRef]

26. Hamed, R.B.; Gomez-Castellanos, J.R.; Henry, L.; Ducho, C.; McDonough, M.A.; Schofield, C.J. The enzymes of $\beta$-lactam biosynthesis. Nat. Prod. Rep. 2013, 30, 21-107. [CrossRef]

27. Bachmann, B.; Li, R.; Townsend, C. beta-Lactam synthetase: A new biosynthetic enzyme. Proc. Natl. Acad. Sci. USA 1998, 95, 9082-9086. [CrossRef]

28. Bachmann, B.O.; Townsend, C.A. Kinetic mechanism of the $\beta$-lactam synthetase of streptomyces clavuligerus. Biochemistry 2000, 39, 11187-11193. [CrossRef]

29. Tahlan, K.; Park, H.U.; Wong, A.; Beatty, P.H.; Jensen, S.E. Two Sets of Paralogous Genes Encode the Enzymes Involved in the Early Stages of Clavulanic Acid and Clavam Metabolite Biosynthesis in Streptomyces clavuligerus. Antimicrob. Agents Chemother. 2004, 48, 930-939. [CrossRef]

30. Salowe, S.P.; Marsh, E.N.; Townsend, C.A. Purification and characterization of clavaminate synthase from Streptomyces clavuligerus: An unusual oxidative enzyme in natural product biosynthesis. Biochemistry 1990, 29, 6499-6508. [CrossRef]

31. Busby, R.W.; Chang, M.D.-T.; Busby, R.C.; Wimp, J.; Townsend, C.A. Expression and Purification of Two Isozymes of Clavaminate Synthase and Initial Characterization of the Iron Binding Site. J. Biol. Chem. 1995, 270, 4262-4269. [CrossRef]

32. Zhang, Z.; Ren, J.S.; Harlos, K.; McKinnon, C.H.; Clifton, I.J.; Schofield, C.J. Crystal structure of a clavaminate synthase-Fe(II)-2oxoglutarate-substrate-NO complex: Evidence for metal centered rearrangements. FEBS Lett. 2002, 517, 7-12. [CrossRef]

33. Caines, M.E.C.; Elkins, J.M.; Hewitson, K.S.; Schofield, C.J. Crystal Structure and Mechanistic Implications of N 2-(2Carboxyethyl)arginine Synthase, the First Enzyme in the Clavulanic Acid Biosynthesis Pathway. J. Biol. Chem. 2004, 279, 5685-5692. [CrossRef] [PubMed]

34. Wu, T.K.; Busby, R.W.; Houston, T.A.; Mcilwaine, D.B.; Egan, L.A.; Townsend, C.A.; Wu, T.; Busby, R.W.; Houston, T.A.; Ilwaine, D.B.M.C.; et al. Identification, Cloning, Sequencing, and overexpression of the gene encoding proclavaminate amidino hydrolase and characterization of protein function in clavulanic acid biosynthesis. J. Bacteriol. 1995, 177, 3714-3720. [CrossRef] [PubMed]

35. Shrestha, B.; Dhakal, D.; Darsandhari, S.; Pandey, R.P.; Pokhrel, A.R.; Jnawali, H.N.; Sohng, J.K. Heterologous production of clavulanic acid intermediates in Streptomyces venezuelae. Biotechnol. Bioprocess. Eng. 2017, 22, 359-365. [CrossRef]

36. Ramirez-Malule, H.; Restrepo, A.; Cardona, W.; Junne, S.; Neubauer, P.; Rios-Estepa, R. Inversion of the stereochemical configuration (3S, 5S)-clavaminic acid into (3R, 5R)-clavulanic acid: A computationally-assisted approach based on experimental evidence. J. Theor. Biol. 2016, 395, 40-50. [CrossRef]

37. Arulanantham, H.; Kershaw, N.J.; Hewitson, K.S.; Hughes, C.E.; Thirkettle, J.E.; Schofield, C.J. ORF17 from the clavulanic acid biosynthesis gene cluster catalyzes the ATP-dependent formation of N-glycyl-clavaminic acid. J. Biol. Chem. 2006, 281, 279-287. [CrossRef]

38. MacKenzie, A.K.; Kershaw, N.J.; Hernandez, H.; Robinson, C.V.; Schofield, C.J.; Andersson, I. Clavulanic Acid Dehydrogenase: Structural and Biochemical Analysis of the Final Step in the Biosynthesis of the $\beta$-Lactamase Inhibitor Clavulanic Acid. Biochemistry 2007, 46, 1523-1533. [CrossRef]

39. Gómez, S.; Ramírez-Malule, H.; Cardona-G, W.; Osorio, E.; Restrepo, A. Double-Ring Epimerization in the Biosynthesis of Clavulanic Acid. J. Phys. Chem. A 2020, 124, 9413-9426. [CrossRef]

40. Zelyas, N.J.; Cai, H.; Kwong, T.; Jensen, S.E. Alanylclavam biosynthetic genes are clustered together with one group of clavulanic acid biosynthetic genes in Streptomyces clavuligerus. J. Bacteriol. 2008, 190, 7957-7965. [CrossRef]

41. Nobary, S.G.; Jensen, S.E. A comparison of the clavam biosynthetic gene clusters in Streptomyces antibioticus Tü1718 and Streptomyces clavuligerus. Can. J. Microbiol. 2012, 58, 413-425. [CrossRef]

42. Bushell, M.E.; Kirk, S.; Zhao, H.-J.; Avignone-Rossa, C.A. Manipulation of the physiology of clavulanic acid biosynthesis with the aid of metabolic flux analysis. Enzyme Microb. Technol. 2006, 39, 149-157. [CrossRef]

43. Ramirez-Malule, H.; Junne, S.; Nicolás Cruz-Bournazou, M.; Neubauer, P.; Ríos-Estepa, R. Streptomyces clavuligerus shows a strong association between TCA cycle intermediate accumulation and clavulanic acid biosynthesis. Appl. Microbiol. Biotechnol. 2018, 102, 4009-4023. [CrossRef] [PubMed]

44. Sánchez, C.; Quintero, J.C.; Ochoa, S. Flux balance analysis in the production of clavulanic acid by Streptomyces clavuligerus. Biotechnol. Prog. 2015, 31, 1226-1236. [CrossRef] [PubMed]

45. Cavallieri, A.P.; Baptista, A.S.; Leite, C.A.; da Costa Araujo, M.L.G. A case study in flux balance analysis: Lysine, a cephamycin C precursor, can also increase clavulanic acid production. Biochem. Eng. J. 2016, 112, 42-53. [CrossRef]

46. Kenig, M.; Reading, C. Holomycin and an antibiotic (mm 19290) related to tunicamycin, metabolites of streptomyces clavuligerus. J. Antibiot. 1979, 32, 549-554. [CrossRef] [PubMed] 
47. Antonio, T.; Bellão, C.; Corrêa, T.; Cavallieri, A.P.; Badino, A.C.; da Costa Araujo, M.L.G. Evaluation of different media for the production of cephalosporins by streptomyces clavuligerus ATCC 27064. Braz. Arch. Biol. Technol. 2012, 55, 819-825. [CrossRef]

48. Goo, K.S.; Chua, C.S.; Sim, T.S. Directed evolution and rational approaches to improving Streptomyces clavuligerus deacetoxycephalosporin C synthase for cephalosporin production. J. Ind. Microbiol. Biotechnol. 2009, 36, 619-633. [CrossRef]

49. Öster, L.M.; Lester, D.R.; van Scheltinga, A.T.; Svenda, M.; van Lun, M.; Généreux, C.; Andersson, I. Insights into Cephamycin Biosynthesis: The Crystal Structure of CmcI from Streptomyces clavuligerus. J. Mol. Biol. 2006, 358, 546-558. [CrossRef]

50. Liras, P. Holomycin, a dithiolopyrrolone compound produced by Streptomyces clavuligerus. Appl. Microbiol. Biotechnol. 2014, 98, 1023-1030. [CrossRef]

51. Sim, J.; Sim, T.S. In vitro conversion of penicillin G and ampicillin by recombinant Streptomyces clavuligerus NRRL 3585 deacetoxycephalosporin C synthase. Enzyme Microb. Technol. 2001, 29, 240-245. [CrossRef]

52. Law, K.H.; Tsang, M.W.; Wong, Y.K.; Tsang, M.S.; Lau, P.Y.; Wong, K.Y.; Ho, K.P.; Leung, Y.C. Efficient production of secretory streptomyces clavuligerus $\beta$-lactamase inhibitory protein (Blip) in pichia pastoris. AMB Express 2018, 8, 1-11. [CrossRef] [PubMed]

53. Paradkar, A.S.; Petrich, A.K.; Leskiw, B.K.; Aidoo, K.A.; Jensen, S.E. Transcriptional analysis and heterologous expression of the gene encoding $\beta$-lactamase inhibitor protein (BLIP) from Streptomyces clavuligerus. Gene 1994, 144, 31-36. [CrossRef]

54. Doran, J.L.; Leskiw, B.K.; Aippersbach, S.; Jensen, S.E. Isolation and Characterization of a $\beta$-Lactamase-Inhibitory Protein from Streptomyces Clavuligerus and Cloning and Analysis of the Corresponding Gene. J. Bacteriol. 1990, 172, 4909-4918. [CrossRef] [PubMed]

55. Ser, H.-L.; Law, J.W.-F.; Chaiyakunapruk, N.; Jacob, S.A.; Palanisamy, U.D.; Chan, K.-G.; Goh, B.-H.; Lee, L.-H. Fermentation Conditions that Affect Clavulanic Acid Production in Streptomyces clavuligerus: A Systematic Review. Front. Microbiol. 2016, 7, 522. [CrossRef] [PubMed]

56. Sanches Henao, C.P.; Gomez Grimaldos, N.A.; Quintero Diaz, J.C. Producción de acido clavulánico por fermentación de streptomyces clavuligerus: Evaluación de diferentes medios de cultivo y modelado matemático. Dyna 2012, 79, 158-165.

57. Bellão, C.; Antonio, T.; Araujo, M.L.G.C.; Badino, A.C. Production of clavulanic acid and cephamycin c by streptomyces clavuligerus under different fed-batch conditions. Braz. J. Chem. Eng. 2013, 30, 257-266. [CrossRef]

58. Saudagar, P.S.; Singhal, R.S. Optimization of nutritional requirements and feeding strategies for clavulanic acid production by Streptomyces clavuligerus. Bioresour. Technol. 2007, 98, 2010-2017. [CrossRef]

59. Bussari, B.; Saudagar, P.S.; Shaligram, N.S.; Survase, S.A.; Singhal, R.S. Production of cephamycin C by Streptomyces clavuligerus NT4 using solid-state fermentation. J. Ind. Microbiol. Biotechnol. 2008, 35, 49-58. [CrossRef]

60. da Silva Rodrigues, K.C.; de Souza, A.T.; Badino, A.C.; Pedrolli, D.B.; Cerri, M.O. Biotechnology and Industrial Microbiology Screening of medium constituents for clavulanic acid production by Streptomyces clavuligerus. Braz. J. Microbiol. 2018, 49, 832-839. [CrossRef]

61. Neto, A.B.; Hirata, D.B.; Cassiano Filho, L.C.M.; Bellão, C.; Badino, A.C., Jr.; Hokka, C.O. A study on clavulanic acid production by Streptomyces clavuligerus in batch, FED-batch and continuous processes. Braz. J. Chem. Eng. 2005, 22, 557-563. [CrossRef]

62. Teodoro, J.C.; Araujo, M.L.G.C.; Hokka, C.O.; Badino, A.C. Influence of glycerol and ornithine feeding on clavulanic acid production by Streptomyces clavuligerus. Braz. J. Chem. Eng. 2010, 27, 499-506. [CrossRef]

63. Domingues, L.C.G.; Teodoro, J.C.; Hokka, C.O.; Badino, A.C.; Araujo, M.L.G.C. Optimisation of the glycerol-to-ornithine molar ratio in the feed medium for the continuous production of clavulanic acid by Streptomyces clavuligerus. Biochem. Eng. J. 2010, 53, 7-11. [CrossRef]

64. Salem-Bekhit, M.M.; Alanazi, F.K.; Alsarra, I.A. Improvement and enhancement of clavulanic acid production in Streptomyces clavuligerus using vegetable oils. Afr. J. Biotechnol. 2010, 9, 6806-6812.

65. Young, T.; Li, Y.; Efthimiou, G. Olive Pomace Oil can be Used as an Alternative Carbon Source for Clavulanic Acid Production by Streptomyces clavuligerus. Waste Biomass Valoriz. 2019. [CrossRef]

66. Kim, S.-J.; Kim, J.-O.; Shin, C.-H.; Park, H.W.; Kim, C.-W. An approach to strain improvement and enhanced production of clavulanic acid in Streptomyces clavuligerus. Biosci. Biotechnol. Biochem. 2009, 73, 160-164. [CrossRef]

67. Carvalho, V.; Brandão, J.F.; Brandão, R.; Rangel-yagui, C.O.; Couto, J.A.; Converti, A.; Pessoa, A. Stability of clavulanic acid under variable $\mathrm{pH}$, ionic strength and temperature conditions. A new kinetic approach. Biochem. Eng. J. 2009, 45, 89-93. [CrossRef]

68. Brethauer, S.; Held, M.; Panke, S. Clavulanic Acid Decomposition Is Catalyzed by the Compound Itself and by Its Decomposition Products. J. Pharm. Sci. 2008, 97, 3451-3455. [CrossRef]

69. Marques, D.A.V.; Oliveira, R.P.S.; Perego, P.; Porto, A.L.F.; Pessoa, A.; Converti, A. Kinetic and thermodynamic investigation on clavulanic acid formation and degradation during glycerol fermentation by Streptomyces DAUFPE 3060. Enzyme Microb. Technol. 2009, 45, 169-173. [CrossRef]

70. Rodrigues, K.C.S.; Costa, C.L.L.; Badino, A.C.; Pedrolli, D.B.; Pereira, J.F.B.; Cerri, M.O. Application of Acid and Cold Stresses to Enhance the Production of Clavulanic Acid by Streptomyces clavuligerus. Appl. Biochem. Biotechnol. 2019, 188, 706-719. [CrossRef]

71. Costa, C.L.L.; Badino, A.C. Production of clavulanic acid by Streptomyces clavuligerus in batch cultures without and with glycerol pulses under different temperature conditions. Biochem. Eng. J. 2012, 69, 1-7. [CrossRef] 
72. Yepes-García, J.; Caicedo-Montoya, C.; Pinilla, L.; Toro, L.F.; Ríos-Estepa, R. Morphological differentiation of streptomyces clavuligerus exposed to diverse environmental conditions and its relationship with clavulanic acid biosynthesis. Processes 2020, 8 , 1038. [CrossRef]

73. Yagüe, P.; López-García, M.T.; Rioseras, B.; Sánchez, J.; Manteca, Á. Pre-sporulation stages of Streptomyces differentiation: State-of-the-art and future perspectives. FEMS Microbiol. Lett. 2013, 342. [CrossRef] [PubMed]

74. Yagüe, P.; Lopez-Garcia, M.T.; Rioseras, B.; Sanchez, J.; Manteca, A. New insights on the development of Streptomyces and their relationships with secondary metabolite production. Curr. Trends Microbiol. 2012, 8, 65-73. [PubMed]

75. Olmos, E.; Mehmood, N.; Haj Husein, L.; Goergen, J.L.; Fick, M.; Delaunay, S. Effects of bioreactor hydrodynamics on the physiology of Streptomyces. Bioprocess. Biosyst. Eng. 2013, 36, 259-272. [CrossRef] [PubMed]

76. Alok, S. Effect of Different Impellers and Baffles on Aerobic Stirred Tank Fermenter using Computational Fluid Dynamics. J. Bioprocess. Biotech. 2014, 4, 1. [CrossRef]

77. Hristov, H.V.; Mann, R.; Lossev, V.; Vlaev, S.D. A simplified CFD for three-dimensional analysis of fluid mixing, mass transfer and bioreaction in a fermenter equipped with triple novel geometry impellers. Food Bioprod. Process. 2004, 82, 21-34. [CrossRef]

78. Jin, B.; van Leeuwen, J.H.; Doelle, H.W.; Yu, Q.M. The influence of geometry on hydrodynamic and mass transfer characteristics in an external airlift reactor for the cultivation of filamentous fungi. World J. Microbiol. Biotechnol. 1999, 15, 83-90. [CrossRef]

79. Gómez-Ríos, D.; Junne, S.; Neubauer, P.; Ochoa, S.; Ríos-Estepa, R.; Ramírez-Malule, H. Characterization of the Metabolic Response of Streptomyces clavuligerus to Shear Stress in Stirred Tanks and Single-Use 2D Rocking Motion Bioreactors for Clavulanic Acid Production. Antibiotics 2019, 8, 168. [CrossRef]

80. Xia, X.; Lin, S.; Xia, X.X.; Cong, F.S.; Zhong, J.J. Significance of agitation-induced shear stress on mycelium morphology and lavendamycin production by engineered Streptomyces flocculus. Appl. Microbiol. Biotechnol. 2014, 98, 4399-4407. [CrossRef]

81. Lin, Y.-H.; Hwang, S.-C.J.; Gong, J.T.; Wu, J.-Y.; Chen, K.-C. Using Redox Potential to Detect Microbial Activities During Clavulanic Acid Biosynthesis in Streptomyces clavuligerus. Biotechnol. Lett. 2005, 27, 1791-1795. [CrossRef]

82. Rosa, J.C.; Baptista Neto, A.; Hokka, C.O.; Badino, A.C. Influence of dissolved oxygen and shear conditions on clavulanic acid production by Streptomyces clavuligerus. Bioprocess. Biosyst. Eng. 2005, 27, 99-104. [CrossRef]

83. Bentley, P.H.; Brooks, G.; Gilpin, M.L.; Hunt, E. A new total synthesis of $( \pm$ )-clavulanic acid. Tetrahedron Lett. 1979, 20, 1889-1890. [CrossRef]

84. Bentley, P.H.; Berry, P.D.; Brooks, G.; Gilpin, M.L.; Hunt, E.; Zomaya, I.I. Total synthesis of ( \pm )-clavulanic acid. J. Chem. Soc. Chem. Commun. 1977, 748-749. [CrossRef]

85. Liras, P.; Gomez-Escribano, J.P.; Santamarta, I. Regulatory mechanisms controlling antibiotic production in Streptomyces clavuligerus. J. Ind. Microbiol. Biotechnol. 2008, 35, 667-676. [CrossRef] [PubMed]

86. Huang, J.; Shi, J.; Molle, V.; Sohlberg, B.; Weaver, D.; Bibb, M.J.; Karoonuthaisiri, N.; Lih, C.J.; Kao, C.M.; Buttner, M.J.; et al. Cross-regulation among disparate antibiotic biosynthetic pathways of Streptomyces coelicolor. Mol. Microbiol. 2005, 58, $1276-1287$. [CrossRef] [PubMed]

87. Zhang, K.; Mohsin, A.; Dai, Y.; Ali, M.F.; Chen, Z.; Zhuang, Y.; Chu, J.; Guo, M. Role of a Two-Component Signal Transduction System RspA1/A2 in Regulating the Biosynthesis of Salinomycin in Streptomyces albus. Appl. Biochem. Biotechnol. 2020, 1-15. [CrossRef] [PubMed]

88. Lu, F.; Hou, Y.; Zhang, H.; Chu, Y.; Xia, H.; Tian, Y. Regulatory genes and their roles for improvement of antibiotic biosynthesis in Streptomyces. 3 Biotech 2017, 7, 250. [CrossRef]

89. Pérez-Redondo, R.; Rodríguez-García, A.; Martín, J.F.; Liras, P. The claR gene of Streptomyces clavuligerus, encoding a LysR-type regulatory protein controlling clavulanic acid biosynthesis, is linked to the clavulanate-9-aldehyde reductase (car) gene. Gene 1998, 211, 311-321. [CrossRef]

90. Bignell, D.R.D.; Tahlan, K.; Colvin, K.R.; Jensen, S.E.; Leskiw, B.K. Expression of ccaR, Encoding the Positive Activator of Cephamycin C and Clavulanic Acid Production in Streptomyces clavuligerus, Is Dependent on bldG. Antimicrob. Agents Chemother. 2005, 49, 1529-1541. [CrossRef]

91. Kurt, A.; Álvarez-Álvarez, R.; Liras, P.; Özcengiz, G. Role of the cmcH-ccaR intergenic region and ccaR overexpression in cephamycin C biosynthesis in Streptomyces clavuligerus. Appl. Microbiol. Biotechnol. 2013, 97, 5869-5880. [CrossRef]

92. Pinilla, L.; Toro, L.F.; Laing, E.; Alzate, J.F.; Ríos-Estepa, R. Comparative transcriptome analysis of streptomyces clavuligerus in response to favorable and restrictive nutritional conditions. Antibiotics 2019, 8, 96. [CrossRef] [PubMed]

93. Pérez-Llarena, F.J.; Liras, P.; Rodríguez-García, A.; Martín, J.F. A regulatory gene (ccaR) required for cephamycin and clavulanic acid production in Streptomyces clavuligerus: Amplification results in overproduction of both beta-lactam Compounds. J. Bacteriol. 1997, 179, 2053-2059. [CrossRef] [PubMed]

94. Alexander, D.C.; Jensen, S.E. Investigation of the Streptomyces clavuligerus Cephamycin C Gene Cluster and Its Regulation by the CcaR Protein. J. Bacteriol. 1998, 180, 4068-4079. [CrossRef] [PubMed]

95. Kurt Kizildoğan, A.; Vanli Jaccard, G.; Mutlu, A.; Sertdemir, İ.; Özcengiz, G. Genetic engineering of an industrial strain of Streptomyces clavuligerus for further enhancement of clavulanic acid production. Turk. J. Biol. 2017, 41, 342-353. [CrossRef]

96. Qin, R.; Zhong, C.; Zong, G.; Fu, J.; Pang, X.; Cao, G. Improvement of clavulanic acid production in Streptomyces clavuligerus F613-1 by using a claR-neo reporter strategy. Electron. J. Biotechnol. 2017, 28, 41-46. [CrossRef] 
97. Cho, H.S.; Jo, J.C.; Shin, C.-H.; Lee, N.; Choi, J.-S.; Cho, B.-K.; Roe, J.-H.; Kim, C.-W.; Kwon, H.J.; Yoon, Y.J. Improved production of clavulanic acid by reverse engineering and overexpression of the regulatory genes in an industrial Streptomyces clavuligerus strain. J. Ind. Microbiol. Biotechnol. 2019, 46, 1205-1215. [CrossRef]

98. Santamarta, I.; López-García, M.T.; Pérez-Redondo, R.; Koekman, B.; Martín, J.F.; Liras, P. Connecting primary and secondary metabolism: AreB, an IclR-like protein, binds the AREccaR sequence of $\mathrm{S}$. clavuligerus and modulates leucine biosynthesis and cephamycin C and clavulanic acid production. Mol. Microbiol. 2007, 66, 511-524. [CrossRef]

99. López-García, M.T.; Santamarta, I.; Liras, P. Morphological differentiation and clavulanic acid formation are affected in a Streptomyces clavuligerus adpA-deleted mutant. Microbiology 2010, 156, 2354-2365. [CrossRef]

100. Mascher, T.; Helmann, J.D.; Unden, G. Stimulus Perception in Bacterial Signal-Transducing Histidine Kinases. Microbiol. Mol. Biol. Rev. 2006, 70, 910-938. [CrossRef]

101. Papon, N.; Stock, A.M. Two-component systems. Curr. Biol. 2019, 29, R724-R725. [CrossRef]

102. Fu, J.; Qin, R.; Zong, G.; Liu, C.; Kang, N.; Zhong, C.; Cao, G. The CagRS Two-Component System Regulates Clavulanic Acid Metabolism via Multiple Pathways in Streptomyces clavuligerus F613-1. Front. Microbiol. 2019, 10, 1-17. [CrossRef] [PubMed]

103. Jnawali, H.N.; Oh, T.J.; Liou, K.; Park, B.C.; Sohng, J.K. A two-component regulatory system involved in clavulanic acid production. J. Antibiot. 2008, 61, 651-659. [CrossRef] [PubMed]

104. Kwong, T.; Zelyas, N.J.; Cai, H.; Tahlan, K.; Wong, A.; Jensen, S.E. 5 S clavam biosynthesis is controlled by an atypical twocomponent regulatory system in Streptomyces clavuligerus. Antimicrob. Agents Chemother. 2012, 56, 4845-4855. [CrossRef] [PubMed]

105. Santos-Beneit, F. The Pho regulon: A huge regulatory network in bacteria. Front. Microbiol. 2015, 6, 402. [CrossRef]

106. Salehghamari, E.; Hamedi, J.; Elahi, E.; Sepehrizadeh, Z.; Sadeghi, M.; Muth, G. Prediction of the pho regulon in Streptomyces clavuligerus DSM 738. New Microbiol. 2012, 35, 447-457.

107. Horinouchi, S.; Hara, O.; Beppu, T. Cloning of a pleiotropic gene that positively controls biosynthesis of A-factor, actinorhodin, and prodigiosin in Streptomyces coelicolor A3(2) and Streptomyces lividans. J. Bacteriol. 1983, 155, 1238-1248. [CrossRef]

108. Parajuli, N.; Hung, T.V.; Ishida, K.; Hang, T.T.; Hei, C.L.; Liou, K.; Jae, K.S. Identification and characterization of the afsR homologue regulatory gene from Streptomyces peucetius ATCC 27952. Res. Microbiol. 2005, 156, 707-712. [CrossRef]

109. Fu, J.; Qin, R.; Zong, G.; Zhong, C.; Zhang, P.; Kang, N.; Qi, X.; Cao, G. The two-component system CepRS regulates the cephamycin $C$ biosynthesis in Streptomyces clavuligerus F613-1. AMB Express 2019, 9. [CrossRef]

110. Sun, D.; Liu, C.; Zhu, J.; Liu, W. Connecting metabolic pathways: Sigma factors in Streptomyces spp. Front. Microbiol. 2017, 8, 2546. [CrossRef]

111. Jnawali, H.N.; Liou, K.; Sohng, J.K. Role of $\sigma$-factor (orf21) in clavulanic acid production in Streptomyces clavuligerus NRRL3585. Microbiol. Res. 2011, 166, 369-379. [CrossRef]

112. Baş, L.; Otur, Ç.; Kurt-Kızıldoğan, A. Enhanced Tunicamycin Biosynthesis in BldG Overexpressed Streptomyces clavuligerus. Appl. Biochem. Microbiol. 2020, 56, 412-419. [CrossRef]

113. Chatterji, D.; Kumar Ojha, A. Revisiting the stringent response, ppGpp and starvation signaling. Curr. Opin. Microbiol. 2001, 4, 160-165. [CrossRef]

114. Jin, W.; Ryu, Y.G.; Kang, S.G.; Kim, S.K.; Saito, N.; Ochi, K.; Lee, S.H.; Lee, K.J. Two relAlspoT homologous genes are involved in the morphological and physiological differentiation of Streptomyces clavuligerus. Microbiology 2004, 150, 1485-1493. [CrossRef] [PubMed]

115. Gomez-Escribano, J.P.; Martín, J.F.; Hesketh, A.; Bibb, M.J.; Liras, P. Streptomyces clavuligerus relA-null mutants overproduce clavulanic acid and cephamycin C: Negative regulation of secondary metabolism by (p)ppGpp. Microbiology 2008, 154, 744-755. [CrossRef] [PubMed]

116. Li, R.; Townsend, C.A. Rational strain improvement for enhanced clavulanic acid production by genetic engineering of the glycolytic pathway in Streptomyces clavuligerus. Metab. Eng. 2006, 8, 240-252. [CrossRef] [PubMed]

117. Jnawali, H.N.; Lee, H.C.; Sohng, J.K. Enhancement of clavulanic acid production by expressing regulatory genes in gap gene deletion mutant of Streptomyces clavuligerus NRRL3585. J. Microbiol. Biotechnol. 2010, 20, 146-152. [CrossRef] [PubMed]

118. Medema, M.H.; Alam, M.T.; Heijne, W.H.M.; Van Den Berg, M.A.; Müller, U.; Trefzer, A.; Bovenberg, R.A.L.; Breitling, R.; Takano, E. Genome-wide gene expression changes in an industrial clavulanic acid overproduction strain of Streptomyces clavuligerus. Microb. Biotechnol. 2011, 4, 300-305. [CrossRef] [PubMed]

119. Said, I.G.; Abdelwahed, N.A.M.; Awad, H.M.; Shallan, M.A.; El-Shahed, K.Y.; Abdel-Rahim, E.A. Enhancement of clavulanic acid production by Streptomyces sp MU-NRC77 via mutation and medium optimization. Trop. J. Pharm. Res. 2017, 16, 31-42. [CrossRef]

120. Cruz-Hernández, I.L.; Vasconcelos, E.D.S.; Teodoro, J.C.; De Baptista-Neto, A.; Da Costa Araujo, M.L.G.; Badino, A.C. Exploring the Optimization of UV Mutants of Streptomyces clavuligerus for Clavulanic Acid Production. Microbiol. Res. J. Int. 2019, 26, 1-8. [CrossRef]

121. Song, J.Y.; Jeong, H.; Yu, D.S.; Fischbach, M.A.; Park, H.-S.; Kim, J.J.; Seo, J.-S.; Jensen, S.E.; Oh, T.K.; Lee, K.J.; et al. Draft genome sequence of Streptomyces clavuligerus NRRL 3585, a producer of diverse secondary metabolites. J. Bacteriol. 2010, 192, 6317-6318. [CrossRef] [PubMed] 
122. Medema, M.H.; Trefzer, A.; Kovalchuk, A.; van den Berg, M.; Müller, U.; Heijne, W.; Wu, L.; Alam, M.T.; Ronning, C.M.; Nierman, W.C.; et al. The sequence of a 1.8-mb bacterial linear plasmid reveals a rich evolutionary reservoir of secondary metabolic pathways. Genome Biol. Evol. 2010, 2, 212-224. [CrossRef] [PubMed]

123. Cao, G.; Zhong, C.; Zong, G.; Fu, J.; Liu, Z.; Zhang, G.; Qin, R. Complete Genome Sequence of Streptomyces clavuligerus F613-1, an Industrial Producer of Clavulanic Acid. Genome Announc. 2016, 4, 4-5. [CrossRef] [PubMed]

124. Hwang, S.; Lee, N.; Jeong, Y.; Lee, Y.; Kim, W.; Cho, S.; Palsson, B.O.; Cho, B.-K. Primary transcriptome and translatome analysis determines transcriptional and translational regulatory elements encoded in the Streptomyces clavuligerus genome. Nucleic Acids Res. 2019, 47, 6114-6129. [CrossRef] [PubMed]

125. Lee, N.; Kim, W.; Hwang, S.; Lee, Y.; Cho, S.; Palsson, B.; Cho, B.K. Thirty complete Streptomyces genome sequences for mining novel secondary metabolite biosynthetic gene clusters. Sci. Data 2020, 7, 1-9. [CrossRef] [PubMed]

126. Kim, W.; Hwang, S.; Lee, N.; Lee, Y.; Cho, S.; Palsson, B.; Cho, B.K. Transcriptome and translatome profiles of Streptomyces species in different growth phases. Sci. Data 2020, 7, 1-12. [CrossRef] [PubMed]

127. Álvarez-Álvarez, R.; Rodríguez-García, A.; Santamarta, I.; Pérez-Redondo, R.; Prieto-Domínguez, A.; Martínez-Burgo, Y.; Liras, P. Transcriptomic analysis of $S$ treptomyces clavuligerus $\Delta$ ccaR: Tsr: Effects of the cephamycin C-clavulanic acid cluster regulator CcaR on global regulation. Microb. Biotechnol. 2014, 7, 221-231. [CrossRef]

128. Santamarta, I.; López-García, M.T.; Kurt, A.; Nárdiz, N.; Álvarez-Álvarez, R.; Pérez-Redondo, R.; Martín, J.F.; Liras, P. Characterization of DNA-binding sequences for $\mathrm{CcaR}$ in the cephamycin-clavulanic acid supercluster of Streptomyces clavuligerus. Mol. Microbiol. 2011, 81, 968-981. [CrossRef]

129. Robles-Reglero, V.; Santamarta, I.; Álvarez-álvarez, R.; Martín, J.F.; Liras, P. Transcriptional analysis and proteomics of the holomycin gene cluster in overproducer mutants of Streptomyces clavuligerus. J. Biotechnol. 2013, 163, 69-76. [CrossRef]

130. Martínez-Burgo, Y.; Álvarez-Álvarez, R.; Rodríguez-García, A.; Liras, P. The pathway-specific regulator ClaR of Streptomyces clavuligerus has a global effect on the expression of genes for secondary metabolism and differentiation. Appl. Environ. Microbiol. 2015, 81, 6637-6648. [CrossRef]

131. Álvarez-Álvarez, R.; Rodríguez-García, A.; Martínez-Burgo, Y.; Martín, J.F.; Liras, P. Transcriptional studies on a Streptomyces clavuligerus oppA2 deletion mutant: Nacetylglycyl- clavaminic acid is an intermediate of clavulanic acid biosynthesis. Appl. Environ. Microbiol. 2018, 84. [CrossRef]

132. Nárdiz, N.; Santamarta, I.; Lorenzana, L.M.; Martín, J.F.; Liras, P. A rhodanese-like protein is highly overrepresented in the mutant S. clavuligerus oppA2::aph: Effect on holomycin and other secondary metabolites production. Microb. Biotechnol. 2011, 4, 216-225. [CrossRef] [PubMed]

133. Martínez-Burgo, Y.; Santos-Aberturas, J.; Rodríguez-García, A.; Barreales, E.G.; Tormo, J.R.; Truman, A.W.; Reyes, F.; Aparicio, J.F.; Liras, P. Activation of Secondary Metabolite Gene Clusters in Streptomyces clavuligerus by the PimM Regulator of Streptomyces natalensis. Front. Microbiol. 2019, 10, 1-14. [CrossRef] [PubMed]

134. Ferguson, N.L.; Peña-Castillo, L.; Moore, M.A.; Bignell, D.R.D.; Tahlan, K. Proteomics analysis of global regulatory cascades involved in clavulanic acid production and morphological development in Streptomyces clavuligerus. J. Ind. Microbiol. Biotechnol. 2016, 43, 537-555. [CrossRef] [PubMed]

135. Ünsaldı, E.; Kurt-Kızıldoğan, A.; Voigt, B.; Becher, D.; Özcengiz, G. Proteome-wide alterations in an industrial clavulanic acid producing strain of Streptomyces clavuligerus. Synth. Syst. Biotechnol. 2017, 2, 39-48. [CrossRef]

136. Tahlan, K.; Anders, C.; Wong, A.; Mosher, R.H.; Beatty, P.H.; Brumlik, M.J.; Griffin, A.; Hughes, C.; Griffin, J.; Barton, B.; et al. $5 \mathrm{~S}$ clavam biosynthetic genes are located in both the clavam and paralog gene clusters in Streptomyces clavuligerus. Chem. Biol. 2007, 14, 131-142. [CrossRef] [PubMed]

137. Busche, T.; Tsolis, K.C.; Koepff, J.; Rebets, Y.; Rückert, C.; Hamed, M.B.; Bleidt, A.; Wiechert, W.; Lopatniuk, M.; Yousra, A.; et al. Multi-omics and targeted approaches to determine the role of cellular proteases in streptomyces protein secretion. Front. Microbiol. 2018, 9, 1174. [CrossRef] [PubMed]

138. Sulheim, S.; Kumelj, T.; van Dissel, D.; Salehzadeh-Yazdi, A.; Du, C.; Van Wezel, G.P.; Nieselt, K.; Almaas, E.; Wentzel, A.; Kerkhoven, E.J. Enzyme-constrained models and omics analysis of Streptomyces coelicolor reveal metabolic changes that enhance heterologous production. Iscience 2020, 23, 101525. [CrossRef]

139. Wu, Q.; Ni, M.; Liu, W.C.; Ren, J.H.; Rao, Y.H.; Chen, J.; Lu, C.G. Omics for understanding the mechanisms of Streptomyces lydicus A01 promoting the growth of tomato seedlings. Plant. Soil 2018, 431, 129-141. [CrossRef]

140. Lee, Y.; Lee, N.; Hwang, S.; Kim, K.; Kim, W.; Kim, J.; Cho, S.; Palsson, B.O.; Cho, B.K. System-level understanding of gene expression and regulation for engineering secondary metabolite production in Streptomyces. J. Ind. Microbiol. Biotechnol. 2020, 1-14. [CrossRef]

141. Kim, S.H.; Herazo-Maya, J.D.; Kang, D.D.; Juan-Guardela, B.M.; Tedrow, J.; Martinez, F.J.; Sciurba, F.C.; Tseng, G.C.; Kaminski, N. Integrative phenotyping framework (iPF): Integrative clustering of multiple omics data identifies novel lung disease subphenotypes. BMC Genom. 2015, 16, 924. [CrossRef]

142. Yan, J.; Risacher, S.L.; Shen, L.; Saykin, A.J. Network approaches to systems biology analysis of complex disease: Integrative methods for multi-omics data. Brief. Bioinform. 2017, 19, 1370-1381. [CrossRef] [PubMed]

143. Krishnan, K.C.; Kurt, Z.; Barrere-Cain, R.; Sabir, S.; Das, A.; Floyd, R.; Vergnes, L.; Zhao, Y.; Che, N.; Charugundla, S. Integration of multi-omics data from mouse diversity panel highlights mitochondrial dysfunction in non-alcoholic fatty liver disease. Cell Syst. 2018, 6, 103-115. [CrossRef] [PubMed] 
144. Pinu, F.R.; Beale, D.J.; Paten, A.M.; Kouremenos, K.; Swarup, S.; Schirra, H.J.; Wishart, D. Systems biology and multi-omics integration: Viewpoints from the metabolomics research community. Metabolites 2019, 9, 76. [CrossRef] [PubMed]

145. Kumelj, T.; Sulheim, S.; Wentzel, A.; Almaas, E. Predicting Strain Engineering Strategies Using iKS1317: A Genome-Scale Metabolic Model of Streptomyces coelicolor. Biotechnol. J. 2019, 14, 1800180. [CrossRef]

146. Scobie, D.; Hjorleifsson, G.; Herron, P.; Rogers, S.; Duncan, K. The Missing Link: Developing a pipeline for accelerated antibiotic discovery from Streptomyces through linking 'omics data. Access Microbiol. 2020, 2, 753. [CrossRef]

147. Jamil, I.N.; Remali, J.; Azizan, K.A.; Nor Muhammad, N.A.; Arita, M.; Goh, H.H.; Aizat, W.M. Systematic Multi-Omics Integration (MOI) Approach in Plant Systems Biology. Front. Plant Sci. 2020, 11. [CrossRef]

148. Gutierrez, J.M.; Feizi, A.; Li, S.; Kallehauge, T.B.; Hefzi, H.; Grav, L.M.; Ley, D.; Baycin Hizal, D.; Betenbaugh, M.J.; Voldborg, B.; et al. Genome-scale reconstructions of the mammalian secretory pathway predict metabolic costs and limitations of protein secretion. Nat. Commun. 2020, 11, 1-10. [CrossRef]

149. López-Agudelo, V.A.; Baena, A.; Ramirez-Malule, H.; Ochoa, S.; Barrera, L.F.; Ríos-Estepa, R. Metabolic adaptation of two in silico mutants of Mycobacterium tuberculosis during infection. BMC Syst. Biol. 2017, 11, 107. [CrossRef]

150. Baloni, P.; Funk, C.C.; Yan, J.; Yurkovich, J.T.; Kueider-Paisley, A.; Nho, K.; Heinken, A.; Jia, W.; Mahmoudiandehkordi, S.; Louie, G.; et al. Metabolic Network Analysis Reveals Altered Bile Acid Synthesis and Cholesterol Metabolism in Alzheimer's Disease. SSRN Electron. J. 2020. [CrossRef]

151. Greenhalgh, K.; Ramiro-Garcia, J.; Heinken, A.; Ullmann, P.; Bintener, T.; Pacheco, M.P.; Baginska, J.; Shah, P.; Frachet, A.; Halder, R.; et al. Integrated In Vitro and In Silico Modeling Delineates the Molecular Effects of a Synbiotic Regimen on Colorectal-Cancer-Derived Cells. Cell Rep. 2019, 27, 1621-1632.e9. [CrossRef]

152. Peñalver Bernabé, B.; Thiele, I.; Galdones, E.; Siletz, A.; Chandrasekaran, S.; Woodruff, T.K.; Broadbelt, L.J.; Shea, L.D. Dynamic genome-scale cell-specific metabolic models reveal novel inter-cellular and intra-cellular metabolic communications during ovarian follicle development. BMC Bioinform. 2019, 20, 1-16. [CrossRef] [PubMed]

153. Mccloskey, D.; Gangoiti, J.A.; King, Z.A.; Naviaux, R.K.; Barshop, B.A.; Palsson, B.O.; Feist, A.M. A model-driven quantitative metabolomics analysis of aerobic and anaerobic metabolism in E. coli K-12 MG1655 that is biochemically and thermodynamically consistent. Biotechnol. Bioeng. 2014, 111, 803-815. [CrossRef] [PubMed]

154. Kleessen, S.; Irgang, S.; Klie, S.; Giavalisco, P.; Nikoloski, Z. Integration of transcriptomics and metabolomics data specifies the metabolic response of Chlamydomonas to rapamycin treatment. Plant J. 2015, 81, 822-835. [CrossRef] [PubMed]

155. Pacheco, M.P.; Bintener, T.; Ternes, D.; Kulms, D.; Haan, S.; Letellier, E.; Sauter, T. Identifying and targeting cancer-specific metabolism with network-based drug target prediction. EBioMedicine 2019, 43, 98-106. [CrossRef] [PubMed]

156. Hastings, J.; Mains, A.; Virk, B.; Rodriguez, N.; Murdoch, S.; Pearce, J.; Bergmann, S.; Le Novère, N.; Casanueva, O. Multi-omics and genome-scale modeling reveal a metabolic shift during C. elegans aging. Front. Mol. Biosci. 2019, 6, 2. [CrossRef]

157. Bordbar, A.; Monk, J.M.; King, Z.A.; Palsson, B.O. Constraint-based models predict metabolic and associated cellular functions. Nat. Rev. Genet. 2014, 15, 107-120. [CrossRef] [PubMed]

158. Feist, A.M.; Palsson, B.O. The biomass objective function. Curr. Opin. Microbiol. 2010, 13, 344-349. [CrossRef] [PubMed]

159. Thiele, I.; Palsson, B.Ø. A protocol for generating a high-quality genome-scale metabolic reconstruction. Nat. Protoc. 2010, 5, 93. [CrossRef] [PubMed]

160. Orth, J.D.; Thiele, I.; Palsson, B.O. What is flux balance analysis? Nat. Biotechnol. 2010, 28, 245-248. [CrossRef] [PubMed]

161. Gianchandani, E.P.; Chavali, A.K.; Papin, J.A. The application of flux balance analysis in systems biology. Wiley Interdiscip. Rev. Syst. Biol. Med. 2010, 2, 372-382. [CrossRef] [PubMed]

162. Razmilic, V.; Castro, J.F.; Andrews, B.; Asenjo, J.A. Analysis of metabolic networks of Streptomyces leeuwenhoekii C34 by means of a genome scale model: Prediction of modifications that enhance the production of specialized metabolites. Biotechnol. Bioeng. 2018, 115, 1815-1828. [CrossRef] [PubMed]

163. Amara, A.; Takano, E.; Breitling, R. Development and validation of an updated computational model of Streptomyces coelicolor primary and secondary metabolism. BMC Genom. 2018, 19, 519. [CrossRef] [PubMed]

164. Wang, C.; Liu, J.; Liu, H.; Wang, J.; Wen, J. A genome-scale dynamic flux balance analysis model of Streptomyces tsukubaensis NRRL18488 to predict the targets for increasing FK506 production. Biochem. Eng. J. 2017, 123, 45-56. [CrossRef]

165. Toro, L.; Pinilla, L.; Avignone-Rossa, C.; Ríos-Estepa, R. An enhanced genome-scale metabolic reconstruction of Streptomyces clavuligerus identifies novel strain improvement strategies. Bioprocess. Biosyst. Eng. 2018, 41, 657-669. [CrossRef] [PubMed]

166. Gómez-Cerón, S.; Galindo-Betancur, D.; Ramírez-Malule, H. Data set of in silico simulation for the production of clavulanic acid and cephamycin C by Streptomyces clavuligerus using a genome scale metabolic model. Data Br. 2019, 24, 103992. [CrossRef] [PubMed]

167. Kirk, S.; Avignone-rossa, C.A.; Bushell, M.E. Growth limiting substrate affects antibiotic production and associated metabolic fluxes in Streptomyces clavuligerus. Biotechnol. Lett. 2000, 22, 1803-1809. [CrossRef]

168. Gómez-Ríos, D.; Ramírez-Malule, H.; Neubauer, P.; Junne, S.; Ríos-Estepa, R. Data of clavulanic acid and clavulanate-imidazole stability at low temperatures. Data Br. 2019, 23, 103775. [CrossRef]

169. Bersanetti, P.A.; Almeida, R.M.R.G.; Barboza, M.; Araújo, M.L.G.C.; Hokka, C.O. Kinetic studies on clavulanic acid degradation. Biochem. Eng. J. 2005, 23, 31-36. [CrossRef]

170. Roubos, J.A.; Krabben, P.; De Laat, W.; Heijnen, J.J. Clavulanic Acid Degradation in Streptomyces clavuligerus Fed-Batch Cultivations. Biotechnol. Prog. 2002, 18, 451-457. [CrossRef] 
171. Ramirez-Malule, H.; Junne, S.; López, C.; Zapata, J.; Sáez, A.; Neubauer, P.; Rios-Estepa, R. An improved HPLC-DAD method for clavulanic acid quantification in fermentation broths of Streptomyces clavuligerus. J. Pharm. Biomed. Anal. 2016, 120, $241-247$. [CrossRef]

172. Vahdat, L.; Sunderland, V.B. Kinetics of amoxicillin and clavulanate degradation alone and in combination in aqueous solution under frozen conditions. Int. J. Pharm. 2007, 342, 95-104. [CrossRef] [PubMed]

173. Peace, N.; Olubukola, O.; Moshood, A. Stability of reconstituted amoxicillin clavulanate potassium under simulated in-home storage conditions. J. Appl. Pharm. Sci. 2012, 2, 28-31.

174. Nur, A.O.; Hassan, A.A.; Gadkariem, E.A.; Osman, Z. Stability of Co-Amoxiclav Reconstituted Injectable Solution. Eur. J. Pharm. Med. Res. 2015, 2, 109-123.

175. Jerzsele, Á.; Nagy, G. The stability of amoxicillin trihydrate and potassium clavulanate combination in aqueous solutions. Acta Vet. Hung. 2009, 57, 485-493. [CrossRef] [PubMed]

176. Gómez-Ríos, D.; Ramírez-Malule, H.; Neubauer, P.; Junne, S.; Ríos-Estepa, R. Degradation Kinetics of Clavulanic Acid in Fermentation Broths at Low Temperatures. Antibiotics 2019, 8, 6. [CrossRef] [PubMed]

177. Jin, X.; Cao, G.; Zhang, X.; Chen, Y.; Wang, L.; Zhong, C. Studies on the formation and synthetic mechanism of related substance $\mathrm{G}$ in potassium clavulanate production. Braz. J. Pharm. Sci. 2015, 51,77-83. [CrossRef]

178. Forte, M.B.S.; Rodrigues, M.I.; Filho, F.M. Clavulanic Acid Adsorption Studies in Zeolites. Adsorpt. Sci. Technol. 2011, 29 , 391-403. [CrossRef]

179. Forte, M.B.S.; Mazutti, M.A.; Filho, F.M.; Rodrigues, M.I. Evaluation of kinetic and mass transfer parameters for adsorption of clavulanic acid into natural and synthetic zeolites. Biotechnol. Bioprocess. Eng. 2011, 16, 1223-1230. [CrossRef]

180. Barboza, M.; Almeida, R.M.R.G.; Hokka, C.O. Kinetic studies of clavulanic acid recovery by ion exchange chromatography. Bioseparation 2001, 10, 221-227. [CrossRef]

181. Barboza, M.; Almeida, R.M.R.G.; Hokka, C.O. Influence of temperature on the kinetics of adsorption and desorption of clavulanic acid by ionic exchange. Biochem. Eng. J. 2003, 14, 19-26. [CrossRef]

182. Almeida, R.M.R.G.; Barboza, M.; Hokka, C.O. Continuous Clavulanic Acid Adsorption Process. In Biotechnology for Fuels and Chemicals; Davison, B.H., Lee, J.W., Finkelstein, M., McMillan, J.D., Eds.; Humana Press: Totowa, NJ, USA, 2003 ; pp. 867-879. ISBN 978-1-4612-0057-4.

183. Cuel, M.; Barboza, M.; Hokka, C.; Kwong, W. Heterogeneous Model of the Process of Clavulanic Acid Purification by Ionic Exchange in a Fixed-Bed Column. Chem. Prod. Process. Model. 2011, 6. [CrossRef]

184. Forte, M.B.S.; Elias, É.C.L.; Pastore, H.O.; Filho, F.M.; Rodrigues, M.I. Evaluation of Clavulanic Acid Adsorption in MgAl-Layered Double Hydroxides: Kinetic, Equilibrium and Thermodynamic Studies. Adsorpt. Sci. Technol. 2012, 30, 65-80. [CrossRef]

185. Forte, M.B.S.; Taviot-Guého, C.; Leroux, F.; Rodrigues, M.I.; Maugeri Filho, F. Development and characterization of a new adsorbent for biomolecule separation: Intercalation and adsorption of clavulanic acid in layered double hydroxides. J. Chem. Technol. Biotechnol. 2016, 91, 1709-1719. [CrossRef]

186. Forte, M.B.S.; Taviot-Guého, C.; Leroux, F.; Rodrigues, M.I.; Maugeri Filho, F. Clavulanic acid separation on fixed bed columns of layered double hydroxides: Optimization of operating parameters using breakthrough curves. Process. Biochem. 2016, 51, 509-516. [CrossRef]

187. Carneiro-da-Cunha, M.N.; Souza, K.P.S.; Mota, A.M.O.; Teixeira, J.A.; Porto, C.S.; Porto, T.S.; Porto, A.L.F. Stability of clavulanic acid in PEG/citrate and liquid-liquid extraction in aqueous two-phase system. Fluid Phase Equilib. 2014, 375, 104-109. [CrossRef]

188. Videira, M.; Aires-Barros, M.R. Liquid-liquid extraction of clavulanic acid using an aqueous two-phase system of polyethylene glycol and potassium phosphate. J. Chromatogr. A 1994, 668, 237-240. [CrossRef]

189. Silva, C.S.; Bovarotti, E.; Rodrigues, M.I.; Hokka, C.O.; Barboza, M. Evaluation of the effects of the parameters involved in the purification of clavulanic acid from fermentation broth by aqueous two-phase systems. Bioprocess. Biosyst. Eng. 2009, 32, 625-632. [CrossRef]

190. Pereira, J.F.B.; Santos, V.C.; Johansson, H.O.; Teixeira, J.A.C.; Pessoa, A. A stable liquid-liquid extraction system for clavulanic acid using polymer-based aqueous two-phase systems. Sep. Purif. Technol. 2012, 98, 441-450. [CrossRef]

191. Panas, P.; Lopes, C.; Cerri, M.O.; Ventura, S.P.M.; Santos-Ebinuma, V.C.; Pereira, J.F.B. Purification of clavulanic acid produced by Streptomyces clavuligerus via submerged fermentation using polyethylene glycol/cholinium chloride aqueous two-phase systems. Fluid Phase Equilib. 2017, 450, 42-50. [CrossRef]

192. da Silva, C.S.; Cuel, M.F.; Barreto, V.O.; Kwong, W.H.; Hokka, C.O.; Barboza, M. Separation of clavulanic acid from fermented broth of amino acids by an aqueous two-phase system and ion-exchange adsorption. New Biotechnol. 2012, 29, 428-431. [CrossRef]

193. Viana Marques, D.A.; Pessoa-Júnior, A.; Lima-Filho, J.L.; Converti, A.; Perego, P.; Porto, A.L.F. Extractive fermentation of clavulanic acid by Streptomyces DAUFPE 3060 using aqueous two-phase system. Biotechnol. Prog. 2011, 27, 95-103. [CrossRef] [PubMed]

194. Marques, D.A.V.; Santos-Ebinuma, V.C.; Pessoa-Junior, A.; Porto, A.L.F.; Rivas Torres, B.; Concerti, A. Effect of Aeration and Agitation on Extractive Fermentation of Clavulanic Acid by Using Aqueous Two-phase System. Biotechnol. Prog. 2016, 32, 1444-1452. [CrossRef] [PubMed]

195. Costa, C.L.L.; Badino, A.C. Overproduction of clavulanic acid by extractive fermentation. Electron. J. Biotechnol. 2015, 18, 154-160. [CrossRef] 
196. Guedes De Andrade, E.; De Siqueira Cardoso Silva, M.; Brandão Haga, R.; Carvalho Santos, V.; Pessoa, A., Jr.; Rangel-Yagui, C.D.O. Extraction of clavulanic acid using aqueous two-phase micellar system. Biotechnol. Appl. Biochem. 2011, 58, 103-108. [CrossRef]

197. Santos, V.C.; Hasmann, F.A.; Converti, A.; Pessoa, A. Liquid-liquid extraction by mixed micellar systems: A new approach for clavulanic acid recovery from fermented broth. Biochem. Eng. J. 2011, 56, 75-83. [CrossRef]

198. De Siqueira Cardoso Silva, M.; de Carvalho Santos-Ebinuma, V.; Lopes, A.M.; de Oliveira Rangel-Yagui, C. Dextran sulfate/Triton $\mathrm{X}$ two-phase micellar systems as an alternative first purification step for clavulanic acid. Fluid Phase Equilib. 2015, 399, 80-86. [CrossRef]

199. Brites, L.M.; Oliveira, J.H.; Barboza, M.; Hokka, C.O. Effect of physicochemical properties of solvents on clavulanic acid extraction from fermentation broth. Lat. Am. Appl. Res. 2012, 42, 65-70.

200. de Mancilha, M.A.; Guimarães, G.C.; de Nardi, J.C.S.C.; de Oliveira, J.H.H.L.; Hirata, D.B. Optimization of Liquid-Liquid Extraction Step for Clavulanic Acid From Fermentation Broth Using Solvent Mixtures. Quim. Nova 2014, 37, 1335-1341. [CrossRef]

201. Hirata, D.B.; Oliveira, J.H.H.L.; Leao, K.V.; Rodrigues, M.I.; Ferreira, A.G.; Giulietti, M.; Barboza, M.; Hokka, C.O. Optimization of the precipitation of clavulanic acid from fermented broth using T-octylamine as intermediate. Braz. J. Chem. Eng. 2013, 30, 231-244. [CrossRef]

202. Hirata, D.B.; Oliveira, J.H.H.L.; Leão, K.V.; Rodrigues, M.I.; Ferreira, A.G.; Giulietti, M.; Barboza, M.; Hokka, C.O. Precipitation of clavulanic acid from fermentation broth with potassium 2-ethyl hexanoate salt. Sep. Purif. Technol. 2009, 66, 598-605. [CrossRef] 